\title{
HESSD
}

\section{Vertical hydraulic conductivity of a clayey-silt aquitard: accelerated fluid flow in a centrifuge permeameter compared with in situ conditions}

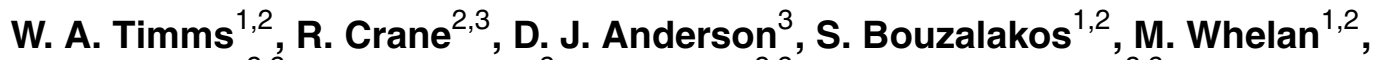 \\ D. McGeeney ${ }^{2,3}$, P. F. Rahman ${ }^{3}$, A. Guinea ${ }^{2,3}$, and R. I. Acworth ${ }^{2,3}$
}

${ }^{1}$ School of Mining Engineering, University of New South Wales, Sydney, Australia

${ }^{2}$ UNSW Connected Waters Initiative affiliated with the National Centre for Groundwater Research and Training Australia, Sydney, Australia

${ }^{3}$ Water Research Laboratory, School of Civil and Environmental Engineering, University of New South Wales, Sydney, Australia

Received: 16 January 2014 - Accepted: 26 February 2014 - Published: 21 March 2014

Correspondence to: W. A. Timms (w.timms@unsw.edu.au)

Published by Copernicus Publications on behalf of the European Geosciences Union.

\section{Vertical hydraulic conductivity of a clayey-silt aquitard \\ W. A. Timms et al.}

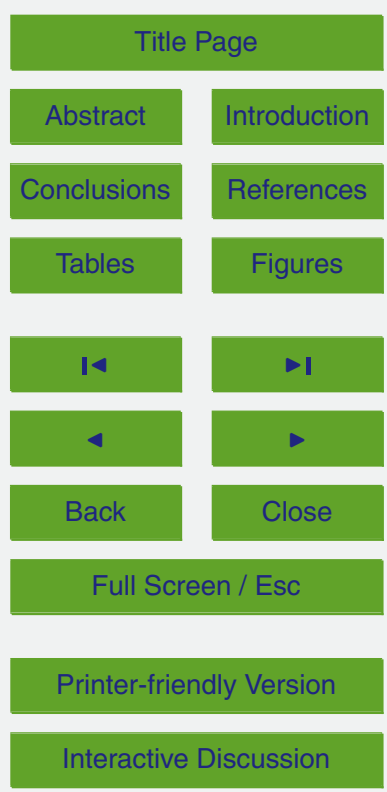




\section{Abstract}

Evaluating the possibility of leakage through low permeability geological strata is critically important for sustainable water supplies, extraction of fuels from strata such as coal beds, and confinement of waste within the earth. Characterizing low or negligi5 ble flow rates and transport of solutes can require impractically long periods of field or laboratory testing, but is necessary for evaluations over regional areas and over multi-decadal timescales. The current work reports a custom designed centrifuge permeameter (CP) system, which can provide relatively rapid and reliable hydraulic conductivity $(K)$ measurement compared to column permeameter tests at standard gravity $10(1 g)$. Linear fluid velocity through a low $K$ porous sample is linearly related to $g$-level during a CP flight unless consolidation or geochemical reactions occur. The CP module is designed to fit within a standard $2 \mathrm{~m}$ diameter, geotechnical centrifuge with a capacity for sample dimensions of 30 to $100 \mathrm{~mm}$ diameter and 30 to $200 \mathrm{~mm}$ in length. At maximum RPM the resultant centrifugal force is equivalent to $550 \mathrm{~g}$ at base of sample 15 or a total stress of $\sim 2 \mathrm{MPa}$. $K$ is calculated by measuring influent and effluent volumes. A custom designed mounting system allows minimal disturbance of drill core samples and a centrifugal force that represents realistic in situ stress conditions is applied. Formation fluids were used as influent to limit any shrink-swell phenomena which may alter the resultant $K$ value. Vertical hydraulic conductivity $\left(K_{\mathrm{v}}\right)$ results from CP test20 ing of core from the sites in the same clayey silt formation varied $\left(10^{-7}\right.$ to $10^{-9} \mathrm{~m} \mathrm{~s}^{-1}$, $n=14$ ) but higher than $1 \mathrm{~g}$ column permeameter tests of adjacent core using deionized water $\left(10^{-9}\right.$ to $\left.10^{-11} \mathrm{~ms}^{-1}, n=7\right)$. Results at one site were similar to in situ $K_{\mathrm{v}}$ values $\left(3 \times 10^{-9} \mathrm{~ms}^{-1}\right)$ from pore pressure responses within a $30 \mathrm{~m}$ clayey sequence in a homogenous area of the formation. $K_{\mathrm{v}}$ sensitivity to sample heterogeneity was obsults demonstrate the utility of centrifuge testing for measuring minimum $K$ values that can contribute to assessments of geological formations at large scale. The importance
Vertical hydraulic conductivity of a clayey-silt aquitard

W. A. Timms et al.

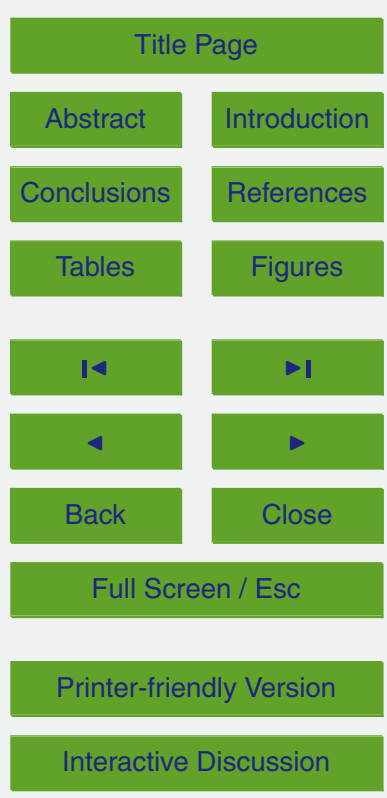


of using realistic stress conditions and influent geochemistry during hydraulic testing is also demonstrated.

\section{Introduction}

Clay or other low permeability sediment and rock often dominate sedimentary se5 quences and can form important hydraulic barriers known as aquitards (Potter et al., 1980). Aquitards often overlie aquifers that yield strategically important fresh water resources, and form important cap-rocks or seals between shallow aquifers and deeper strata that are targeted for depressurization during gas or mineral extraction (Timms et al., 2012). The current work compares the results of steady state centrifuge per10 meability testing of semi-consolidated drill core samples with column tests at standard gravity $\left(1 \mathrm{~g}\right.$ at earth's surface, $9.8065\left(\mathrm{~ms}^{-2}\right)$ and formation scale permeability, based on analysis of in situ pore pressure propagation.

Thick, low $K$, unoxidized, clay-rich aquitards represent important sites for waste confinement and disposal (including high-level radioactive waste and sequestration of car15 bon dioxide and saline effluents) and act as protective covers for regional aquifers (Cherry et al., 2004). Effective shale and claystone flow barriers are required to disconnect shallow aquifer systems from underlying coal seams that are depressurized to produce gas (Timms et al., 2012; APLNG, 2013). Furthermore, fine-grained geologic media are commonly used as engineered barriers to limit horizontal seepage of

20 mine water (Timms et al., 2013), for containment of tailings (Znidarčić et al., 2011) and municipal refuse and nuclear waste (Rowe et al., 1995). Low permeability material is defined by Neuzil (1986) as $K<10^{-8} \mathrm{~ms}^{-1}$. The US EPA requires low permeability waste barriers for hazardous waste landfills with $K$ of $<10^{-9} \mathrm{~ms}^{-1}$ (US EPA, 1989). Neuzil (1986) noted that no geologic material properly tested proved to be entirely impermeable.

Aquitards volumetrically constitute the bulk of sedimentary geologic deposits (Potter et al., 1980), and are typically assumed saturated if located below a watertable
Vertical hydraulic conductivity of a clayey-silt aquitard

W. A. Timms et al.

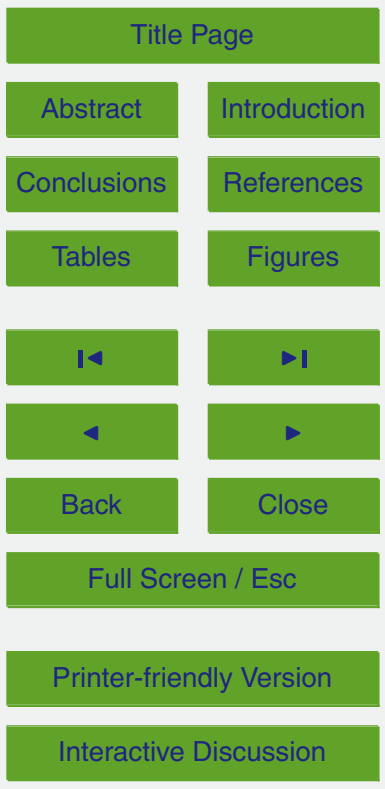


(Cherry et al., 2004). Water-saturated hydraulic conductivity $(K)$ and diffusion coefficients for aquitards may therefore not be applicable to variably saturated or nonwater saturated low permeability strata. Research on aquitards comprised of semiconsolidated clayey materials deposited by alluvial, colluvial and aeolian processes is 5 lacking, compared with aquitard research on glacial tills (Grisak and Cherry, 1975), claystones (Smith et al., 2013; Jougnot et al., 2010) and shale (Neuzil, 1994; Josh et al., 2012). Clay-bearing sediments formed via alluvial, colluvial and aeolian processes frequently occur in the geosphere. For example, clayey silt aquitards account for $60 \%$ of the $\sim 100 \mathrm{~m}$ thick alluvial sediment sequences, in the Mooki catchment of 10 Australia's Murray-Darling Basin (Farley, 2011) this represents a key gap in the current theoretical understanding of clay mineralogy and geochemistry.

Aquitard research on alluvial sediments is important because recharge by slow seepage provides essential groundwater supplies for municipal water supply and crop irrigation in relatively dry inland settings (Acworth and Timms, 2009). Increased effec-

(ease saline water stored within shallow aquitards with implications for continuing high yields of fresh water. Characterising the effects of variable chemical composition of formation water on the hydraulic conductivity of such sediments is therefore essential to determine the long-term hydro-geochemical fate of such field sites.

20 Obtaining realistic measurements of groundwater flow and solute transport within aquitards is by definition a slow process, requiring relatively time consuming and expensive field and laboratory studies. Various field and laboratory methods are available to directly measure or indirectly calculate hydraulic conductivity in a horizontal $\left(K_{\mathrm{h}}\right)$ or vertical $\left(K_{\mathrm{v}}\right)$ orientation, and for saturated and semi-saturated or multi-phase flow (e.g. 25 liquid and gas). Water level recovery of a bore pump test in glacial till $\left(K=10^{-11} \mathrm{~ms}^{-1}\right)$ for example has occurred over a period of $\sim 30$ years, with revised calculation of hydraulic parameters to improve the fit with data that is emerging over this time (van der Kamp, 2011).
HESSD

11, 3155-3212, 2014

Vertical hydraulic conductivity of a clayey-silt aquitard

W. A. Timms et al.

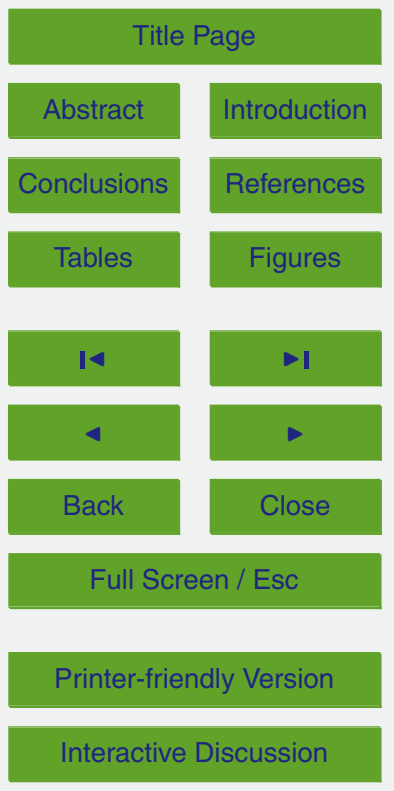


Methods for measuring the in situ permeability of clay formations include: slug tests (piezometer tests, falling-head tests), aquifer pumping tests with piezometers in the aquitard, aquifer pumping tests with observation wells in the aquifer only, measurement of seasonal fluctuations of pore-pressure, measurement of pore-pressure changes and settlement due to surface loading, and numerical analysis of local and regional groundwater flow (van der Kamp, 2001). Neuman and Witherspoon (1968) developed generic analytical solutions for drawdown within an aquiclude, in which vertical flow occurrs, but is sufficient small to have no effect on water levels within an overlying or underlying aquifer. Type curves were presented for analytical solutions applying for an infinitely 10 thick and a finite thickness aquiclude. In contrast, analysis of a leaky aquitard-aquifer system was presented by Neuman and Witherspoon (1972). The ratio method, as it is known, compared drawdown within an aquitard to drawdown in an underlying aquifer from which extraction was occurring. Vertical hydraulic conductivity is calculated from the hydraulic diffusion of pressure transients within a uniform, homogeneous aquitard.

The deconvolution of the pressure response with depth through an aquitard can be analysed with a Fourier transform method known as harmonic analysis (Boldt-Leppin and Hendry, 2003). The hydraulic diffusivity (hydraulic conductivity/specific storage) is expressed analytically either based on the amplitude or phase shift of harmonic signals, assuming that the thickness of the aquitard is half infinite. For example, harmonic analysis enabled in situ $K_{\mathrm{v}}$ to be estimated from phase and amplitude shifts of pore pressure response to soil moisture loading propagating downwards though a $30 \mathrm{~m}$ thick aquitard on the basis of measured specific storage and hourly or 6 hourly groundwater level monitoring over 5 years (Timms and Acworth, 2005). Jiang et al. (2013) further developed the harmonic analysis method for finite aquitards in a multi-layer system, for the case of water level monitoring that is limited to aquifers bounding the aquitard, rather than from within the aquitard. Coherence analysis of water level fluctuations in bounding aquifers from indeterminate stresses (e.g. pumping, recharge, rainfall or earthquake) was used to derive $K_{\mathrm{v}}$ for deep rock aquitards on the basis of interpolated

\section{HESSD}

$11,3155-3212,2014$

\section{Vertical hydraulic conductivity of a clayey-silt aquitard \\ W. A. Timms et al.}

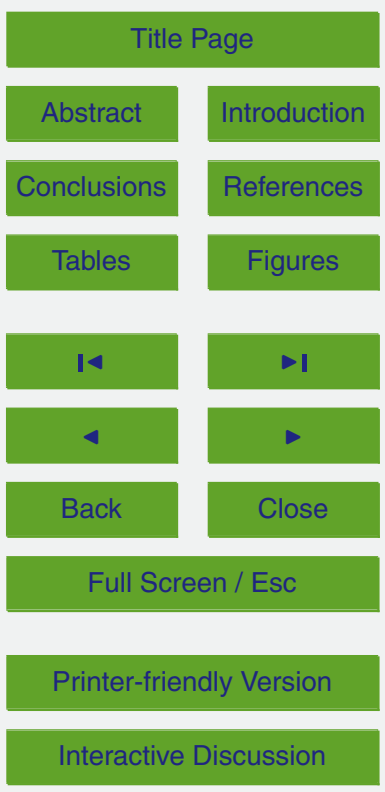


groundwater level data that was measured at irregular intervals of at least 10 days for several decades.

A more direct method of determining in situ hydraulic parameters is possible using fully grouted vibrating wire transducers and high frequency data recording within deep 5 formations, as recently demonstrated by Smith et al. (2013) for a bedrock claystone at up to $325 \mathrm{mb}$.g.l. (below ground level). Pore pressure and barometric pressure were recorded at $30 \mathrm{~min}$ intervals and analysed for barometric response, earth tides, and rainfall events. Core samples from the same drill holes were vacuum sealed on site for consolidation testing and triaxial permeameter testing. The in situ compressibility 10 and specific storage derived from barometric pressure responses were as much as an order of magnitude smaller than laboratory results.

A variety of laboratory testing techniques for low $K$ samples are also available, however, the reliability of results may depend on factors such as the preparation and size of core samples, configuration of equipment and uncertainties of measurement, the 15 infl ans influent water that is used and the stresses that are applied relative to in situ values, and whether permeability is directly measured from steady state flow, or subject to additional parameters and assumptions with alternative flow regime. Laboratory testing of clayey-silt cores by standard rigid and flexible wall column techniques require 1-2 weeks, compared with $<1$ week in a centrifuge permeameter methods for unsaturated samples (ASTM, 2010). Constant or falling-head tests in rigid-walled column permeameters at natural gravity require a large water pressure gradient and/or long testing times for low-permeability samples, are subject to potential leakage, and may not replicate in situ confining stresses. Column testing of core samples is possible for some test conditions in triaxial cells such as those used in geotechnical and petroleum studies, such as the study of Wright et al. (2002) on both $K_{\mathrm{h}}$ and $K_{\mathrm{v}}$ and anisotropy in limestone aquifers. However, standard practice for testing ultralow permeability cores (e.g. $K_{\mathrm{v}}<1 \times 10^{-10} \mathrm{~m} \mathrm{~s}^{-1}$ ) typically consists of applying a confining pressure to a water tight system and measuring relatively subtle changes in pressure with high resolution pressure transducers (API, 1998).

\section{HESSD}

Vertical hydraulic conductivity of a clayey-silt aquitard

W. A. Timms et al.

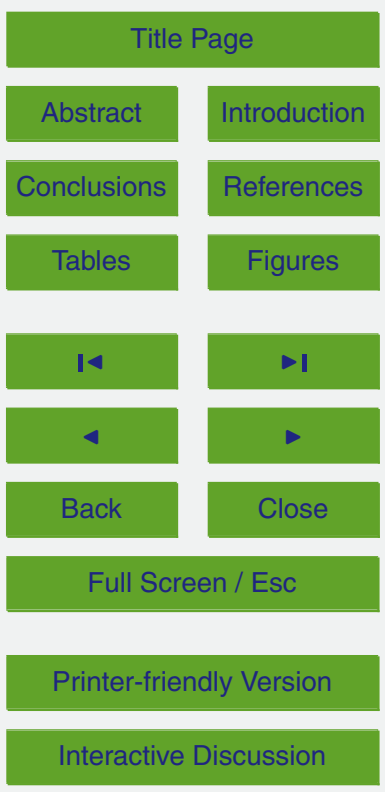


Geotechnical centrifuges are used to subject porous samples to high artificial gravities in order to characterise their hydraulic and/or consolidation properties, and for physical modelling as part of geotechnical design. Accelerated gravity acts on both the solid particles and fluids within the porous sample without a large fluid pressure gra5 dient to drive flow. The technique can be applied to investigate slow hydrogeological processes over shorter timescales, i.e. hydraulic flow through low permeability layers that would take several years under in situ conditions can be reproduced in a geotechnical centrifuge within hour or days, depending on the conditions.

Accelerated gravity achieves a steady state equilibrium for fluid flow within hours 10 matrix. A permeameter column, mounted on a geotechnical centrifuge is rotated sufficiently fast to accelerate flow and approximate in situ total stresses, while the target $g$-level is designed to ensure that the matrix is not consolidated and chemical equilibrium is maintained. Steady state flow can provide more reliable $K$ results than transient less complex instrumentation requirements. Although either steady state or transient flow approaches can be adopted in centrifuge permeameters, steady state flow is relatively straight forward to interpret, depending on the assumptions and instrumentation available to independently measure pressure or suction gradients within the core (Zornberg and McCartney, 20 2010).

The geotechnical centrifuge system that is described in this paper is moderately sized and relatively economic to operate, whilst able to perform both unsaturated and saturated testing of porous media with real-time measurement of various parameters during flight. These attributes mean that centrifuge permeameter testing of relatively

large diameter core (up to $100 \mathrm{~mm}$ diameter) in this facility is comparable in cost to testing of small cores (38 mm diameter) using alternative methods such as He-gas permeation. The system has been successfully used for testing low permeability rock cores (Bouzalakos et al., 2013). To date, there were no other direct $K_{\mathrm{v}}$ measurements on these deep shales available (APLNG, 2013) and alternative laboratory methods
HESSD

11, 3155-3212, 2014

Vertical hydraulic conductivity of a clayey-silt aquitard

W. A. Timms et al.

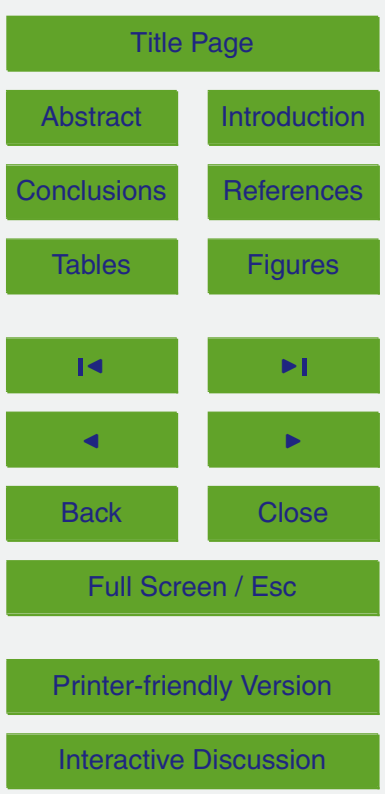


were not successful in obtaining a $K_{\mathrm{v}}$ value from these very low $K$ rocks (Bouzalakos et al., 2013).

This paper demonstrates novel centrifuge permeameter techniques and equipment that have been developed for characterizing semi-consolidated clayey silt cores. Cores 5 were obtained from various low permeability sediments below the watertable at depths of $\sim 10$ to $\sim 40 \mathrm{mb}$.g.l. at sites in eastern Australia. The centrifuge permeameter testing results are compared with $1 \mathrm{~g}$ column permeameter methods and in situ measurements of permeability, based on harmonic analysis of the high frequency pore pressure propagation. The reliability of the $K_{\mathrm{v}}$ results to constrain assessments of regional scale 10 vertical connectivity are considered in the context of sampling and experimental factors including flow and stress conditions within the centrifuge permeameter.

\section{Centrifuge technology for hydraulic characterisation}

\subsection{Centrifugal acceleration}

Centrifugal force is a body force that accelerates both solid and fluid phases within

a core sample. A physical model of identical geologic material that is subjected to centrifugal acceleration experiences stresses equivalent to a full scale in situ prototype (Nimmo and Mello, 1991), where centrifugal acceleration (a) is equal to the scaling factor $(N)$ multiplied by standard gravity $(g)$.

Newtown's second law indicates that centripetal force $(F)$ is required to accelerate $20 \quad\left(a_{r}\right)$ an object with mass $(m)$ to maintain a tangential velocity $(V)$, in a circular path at distance $(r)$ from the axis of rotation. The centripetal force acts towards the centre of rotation along the radius. From a non-inertial frame of reference, for example, on the rotating beam of a centrifuge, a centrifugal force, equal but opposite to the centripetal force, acts outwards from the center of rotation.

$25 \quad F=m a=m V^{2} / r$
HESSD

$11,3155-3212,2014$

Vertical hydraulic conductivity of a clayey-silt aquitard

W. A. Timms et al.

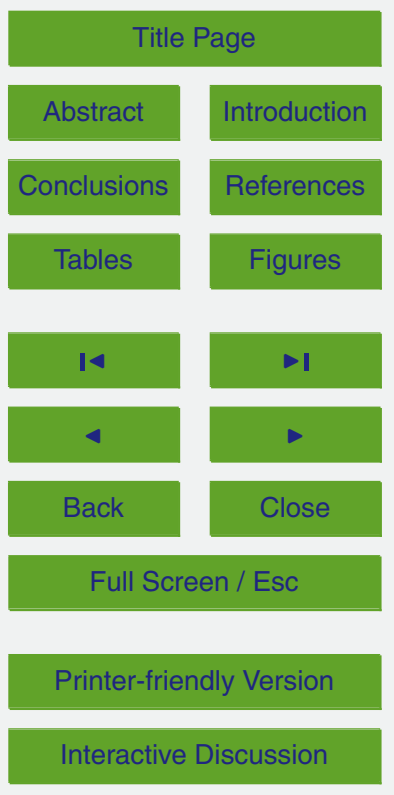


where $a$ is the centrifugal acceleration $\left(\mathrm{ms}^{-2}\right), r$ is the radius from the axis of rotation (m). Since the angular velocity $\omega=v / r$ (radian $^{-1}$ ), we can express the centrifugal force as:

${ }_{5} F=m \omega^{2} r$

Centrifugal force is therefore a body force that accelerates both solid and fluid phases within a core sample. A physical model of identical geologic material that is subjected to centrifugal acceleration experiences stresses equivalent to a full scale in situ prototype (Nimmo and Mello, 1991), where centrifugal acceleration (a) is equal to the scaling factor $(N)$ multiplied by standard gravity $(g)$.

Centrifugal acceleration at any point within the centrifuge core is calculated as follows:

$a=\omega^{2} r=N g$

15 The angular velocity is related to RPM (revolutions $\mathrm{min}^{-1}$ ) as:

$\omega=2 \pi \times \mathrm{RPM} / 60$

Substituting Eq. (4) into Eq. (3) and dividing by $g$ gives Eq. (5) to determine the $N$ scale for a given RPM and radius:

$N=0.001118 \times(\mathrm{RPM})^{2} \times r$

The driving force for fluid flow during centrifugation, and the scale $N$, is therefore directly proportional to the square of rotational speed and radial position of the core sample. The value of $N$ at the mid-height of the core $N_{\text {mid }}$ (Fig. 1) provides a single convenient value of $N$. The variability of $N$ from $r_{0}$ to $r_{i}$ can be minimized for a specified $g$-level by using a centrifuge permeameter with a larger radius and slower angular velocity (Timms, 2009).
HESSD

$11,3155-3212,2014$

Vertical hydraulic conductivity of a clayey-silt aquitard

W. A. Timms et al.

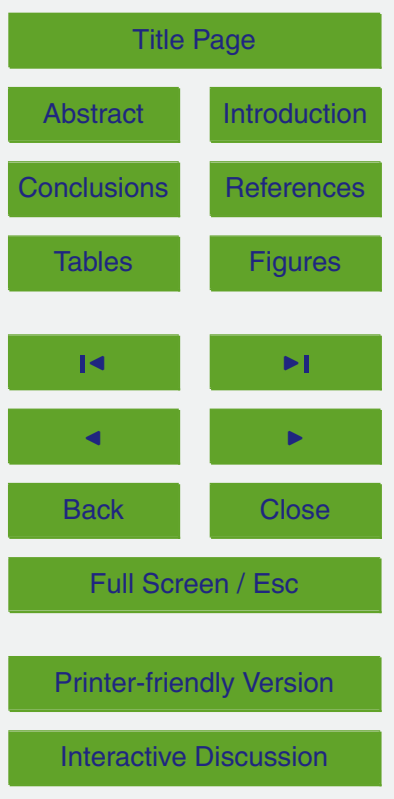

Interactive Discussion 


\subsection{Centrifuge applications for physical modelling and characterisation}

The centrifuge permeameter tests reported herein focus on hydraulic characterisation of intact drill cores, in contrast to the more common application of geotechnical centrifuges for physical modelling of earth systems, such as contaminant transport

5 (Arulanandan et al., 1988), characterizing unsaturated flow parameters (Nakajima and Stadler, 2006) and for physical modelling in geotechnical design (Garnier et al., 2007). For example, a geotechnical centrifuge was used to evaluate the seepage induced consolidation behaviour of mine tailings (Znidarčić et al., 2011).

The use of centrifuge systems has long been recognized as a valid and efficient 10 method to characterize the hydraulic properties of soil, sediment and rock samples (Nimmo and Mello, 1991). Since centrifugal force is a body force experiments can be performed under well controlled conditions with minimal heterogenetic disturbance of the sample. Indeed there are many advantages of centrifugal force as an alternative to high pressure for hydraulic characterisation (Nimmo and Mello, 1991). Advantages include: simplicity and ease of operation, centrifugal methods do not require complex pressure and/or fluid flow apparatus; $K$ range, centrifugal force is determined by the speed of revolution and therefore easily adjustable over a wide range of $K$ values; and time requirements, centrifugal force requires minimal time for a large number of measurements, subject to the saturatation state and permeability of the core.

\subsection{Types of characterisation tests in a centrifuge}

Hydraulic characterisation tests in a centrifuge can be designed with no inflow, steady state flow or transient flow (Table 1). In this context, steady state flow is defined as a constant rate of influent flow that is equivalent to effluent flow. By contrast, transient flow conditions occur when influent and effluent flow rates are not in equilibrium. While
Vertical hydraulic conductivity of a clayey-silt aquitard

W. A. Timms et al.

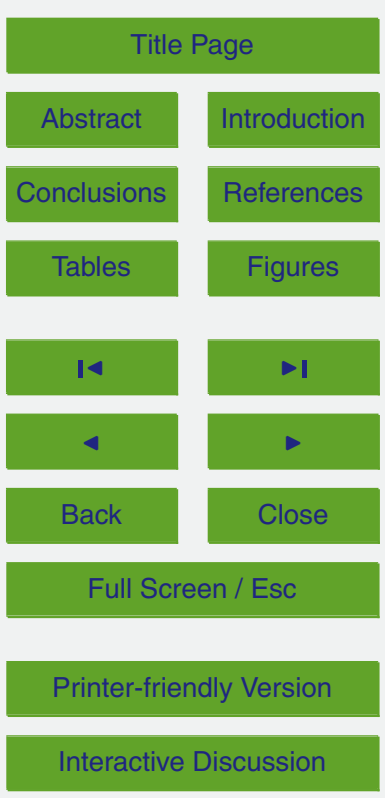
niques based on transient flow, whether one or multiple steps (Nakajima and Stadler, 2006), require specialised pressure transducers or tensiometers. 
Selected examples of the various types of hydraulic characterisation tests are provided in Table 1, with further information on the history and development of centrifuge permeameters for these various testing regimes are provided in Sects. 2.4 and 2.5. In contrast to this study of saturated $K$, no flow and/or transient types of centrifuge 5 tests are used to determine semi-saturated hydraulic parameters. For example, Nakajima and Stadler (2006) used a $2 \mathrm{~m}$ radius centrifuge operating at multiple $g$-levels up to $40 \mathrm{~g}$ for outflow tests to define hydraulic parameters of the van Genuchten model for fluid flow as a function of variable moisture content. This study on fine Ottawa sand samples were tested in a cell of larger dimensions $(102 \mathrm{~mm}$ diameter and up 10 to $432 \mathrm{~mm}$ in height, base of sample at a radius of $1.85 \mathrm{~m}$ ) and transient fluid pressure data, recorded at points along the sample length, were analysed by inverse modelling to resolve optimum hydraulic parameters.

A centrifuge permeameter, or column mounted on a centrifuge strong box, is commonly used for hydraulic characterisation. A conceptual plan of a centrifuge permeame-

shown in Fig. 1. The centrifuge permeameter contains a cylindrical clay sample with length $L$ and diameter $D$, and is spinning in a centrifuge around a central axis at an angular velocity $\omega$. The permeameter has an inlet face at a radius $r$, and a drainage plate at a radius of $r_{0}$. The co-ordinate $z$ is defined as positive from the base of the sample towards the central axis of rotation, consistent with definitions in $1 \mathrm{~g}$ column testing (McCartney, 2010). This frame of reference is in an opposite direction to that defined by Nimmo and Mello (1991), but is convenient for interpretation and comparison of column flow tests. In this study, the outlet face is a free drainage boundary as discussed further in Sects. 2.4, 3.2 and 5.4.

\subsection{History of centrifuge permeameters}

25 Centrifuge permeameter techniques have developed over the past two decades (Nimmo and Mello, 1991; Conca and Wright, 1998; McCartney, 2007; Timms, 2005) to enable fluid flow and contaminant transport studies of aquitard materials that would otherwise not be possible, or studies that would take significantly longer using $1 \mathrm{~g}$ column

\section{HESSD}

11, 3155-3212, 2014

\section{Vertical hydraulic conductivity of a clayey-silt aquitard \\ W. A. Timms et al.}

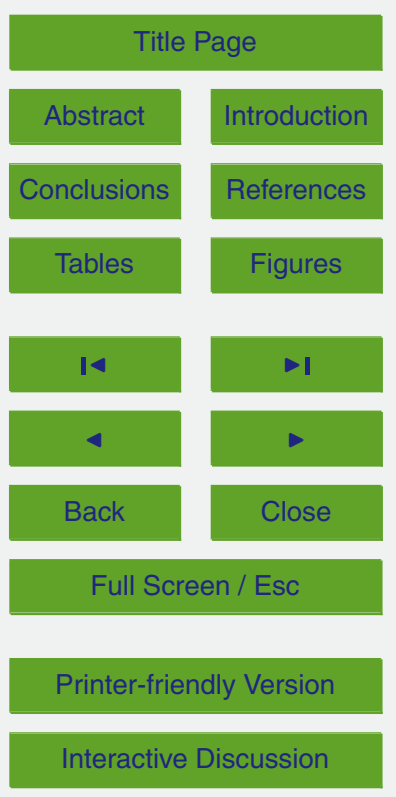


permeameter techniques. Early adaptions of relatively small bench-top centrifuge systems meant that each core could be positioned between fluid filled chambers, with a falling head of ponded fluid above the core and an applied pore pressure at the lower core boundary (Nimmo and Mello, 1991).

5 The Unsaturated Flow Apparatus (UFA) centrifuge system for saturated and unsaturated flow studies introduces influent through a sealed rotary union, with free drainage at the base of each core (Conca and Wright, 1998; Timms, 2003; Timms et al., 2009). However, the radius of this system $(0.087 \mathrm{~m}$ effective to mid-core, or $0.117 \mathrm{~m}$ to base of core) and relatively fast angular velocity results in significantly different $g$-levels and 10 stresses along the length of the core. Furthermore, effective flow measurements are only possible by dissembling the core holder. In comparison, real time monitoring of pore pressure has been proven as successful for larger centrifuge systems (McCartney, 2007).

The centrifuge equipment required for faster testing are a disadvantage to 15 widespread adoption, particularly with advanced instrumentation and data transfer challenges within an accelerated gravity environment. Large geotechnical centrifuges ( 2 to10 $\mathrm{m}$ diameter) are costly to operate and require significant setup time and expertise, whereas the UFA centrifuge is efficient to operate though limited in sample size and the lack of space available to fit instrumentation on the beam for real time data collection (Timms et al., 2003, 2009).

\subsection{NCGRT Broadbent centrifuge permeameter system}

The centrifuge in this study (Fig. 2) is a Broadbent GT-18 Modular Geotechnical Centrifuge (22kW motor drives a variable speed of 10 to $875 \mathrm{RPM}$ ) on which two modules can be fitted: either a centrifuge permeameter GMP GT2/0.65F or a geotechnical beam

GMB GT6/0.75F. The geotechnical beam module is not discussed further in this study. The centrifuge permeameter (CP) module was designed specifically for groundwater research while the base centrifuge and geotechnical beam module are standard. Table 2 describes the specifications and performance details of the centrifuge system 3166

\section{HESSD}

$11,3155-3212,2014$

\section{Vertical hydraulic conductivity of a clayey-silt aquitard \\ W. A. Timms et al.}

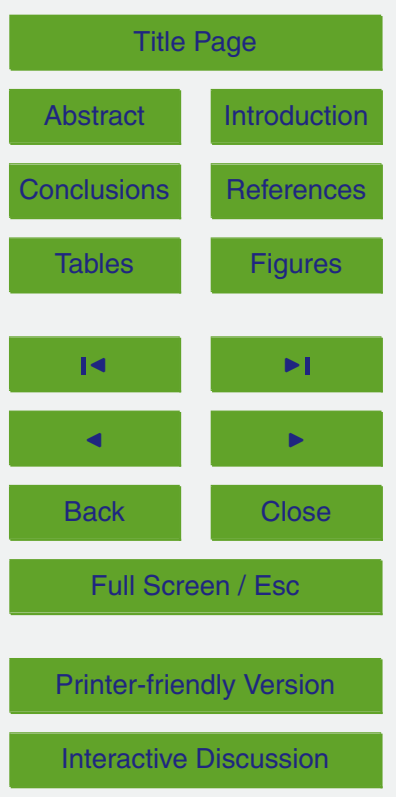


designed by Broadbent and the University of New South Wales. By contrast, the centrifuge permeameter modules on a similar centrifuge at the University of Texas, are of smaller diameter (McCartney, 2007).

The new permeameter permeameter system, including advanced influent and efflu5 ent systems, enables relatively rapid and repeatable testing of large drill core (' $\mathrm{H}$ ' or ' $\mathrm{C}$ ' core diameter 65 to $101 \mathrm{~mm}$, length $30-200 \mathrm{~mm}$ ), with realistic conditions. A low flow rotary union with a capacity of 0.1 to $100 \mathrm{~mL} \mathrm{~min}^{-1}$ connects the influent lines $A$ and $B$ to permeameters 1 and 2 without cross flow between the two influent lines. Unlike UFA centrifuge systems, however, this flow union is not sealed, so the maximum head of 10 fluid within this centrifuge is the radial distance from the rotary union to the top of the sample (a distance of approximately $550 \mathrm{~mm}$ assuming a $100 \mathrm{~mm}$ length of core).

Each centrifuge permeameter (CP) has a maximum sample capacity weight of $4.7 \mathrm{~kg}$. In this system, at maximum centrifuge RPM a maximum of $556 \mathrm{~g}$ applies at the base of the core samples at a radius of $0.65 \mathrm{~m}$ from the centre of rotation. The relatively large CP module allows on-board instrumentation and real-time monitoring of a range of parameters within a pair of permeameter bodies balanced at either end of the rotating beam. Since a maximum $g$-level of 471 applies at the centre of the sample weight, the rating of this module is $2.2 \mathrm{~g}$-ton $(471 \times 4.7 / 1000)$, a relatively small geotechnical centrifuge module (Zornberg and McCartney, 2010). The total weight of each of the pair of centrifuge permeameters when empty is $12.4 \mathrm{~kg}$ plus an allowance of $1.0 \mathrm{~kg}$ of effluent in the reservoir. Routine testing of low permeability porous media is possible with a large cross-sectional flow area (100 $\mathrm{mm}$ diameter), influent pumps with variable speed capable of low flow, and effluent detection systems. Weighting discs to simulate stresses on cores of up to $\sim 2 \mathrm{MPa}$ (at maximum RPM) have also been been developed for consolidated samples that require testing at higher stress.

Additional details on the current setup and instrumentation that has been developed for characterisation of semi-consolidated cores in this geotechnical centrifuge are provided in Sects. 5.2 to 5.5 .

\section{HESSD}

11, 3155-3212, 2014

Vertical hydraulic conductivity of a clayey-silt aquitard

W. A. Timms et al.

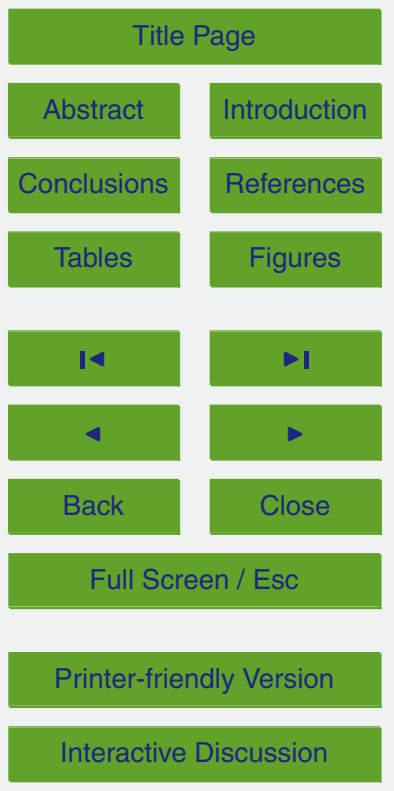




\section{Calculation methods}

\subsection{Intrinsic permeability}

Intrinsic permeability and scaling issues must be considered prior to detailing calculation methods in the following sections. Different combinations of Darcy's Law and scal-

5 ing relationships can be used depending on whether material and hydraulic characterisation or physical modelling is the study objective (Parkes et al., 2011), or geotechnical evaluation where alternative scaling approaches are adopted (e.g. Singh and Gupta, 2000; Nakajima and Stadler, 2006). Incorporating the scaling within the energy gradient that drives flow, as is the approach in this study, is consistent with the fact that if a pressure gradient was applied to a core sample under zero gravity conditions, the hydraulic conductivity would remain equal to the coefficient of proportionality between the applied gradient and the flow rate (Zornberg and McCartney, 2010; Taylor's discussion in Tan and Scott, 1987). For physical modelling of processes such as soil liquefaction however, the scaling that is required for accelerated gravity experiments, could be more appropriate within expressions of permeability or viscosity (Tan and Scott, 1987).

Hydraulic conductivity as a function of intrinsic permeability $(k)$, fluid viscosity and fluid density, is written as

$K=k p_{w} g / u$

20 where $K$ is hydraulic conductivity $\left(\mathrm{m} \mathrm{s}^{-1}\right), p_{w}$ is fluid density $\left(\mathrm{kg} \mathrm{m}^{-3}\right), u$ is fluid viscosity $\left(\mathrm{Nsm}^{-2}=\mathrm{kg} \mathrm{sm}\right)$ and $k$ is intrinsic permeability $\left(\mathrm{m}^{2}\right)$.

However, in studies of relatively shallow and fresh groundwater systems, the fluid viscosity and density are typically constant. In this study, for a shallow and aquitard containing relatively fresh groundwater, permeability refers to a permeability value that has been derived from hydraulic conductivity assuming a fluid viscosity of $1.02 \times 10^{-3} \mathrm{Pas}$ and a fluid density of $1.0 \mathrm{~g} \mathrm{~cm}^{-3}$. Hydraulic conductivity values in this paper are for the saturated state, with cores obtained from below the watertable, preserved and prepared as described in Sect. 5.

Vertical hydraulic conductivity of a clayey-silt aquitard

W. A. Timms et al.

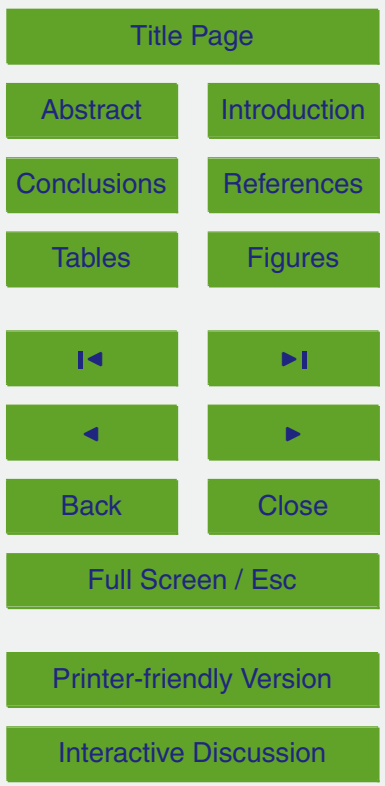




\subsection{Steady state flow hydraulic conductivity measurement}

The specific discharge of water $(v)$ along a groundwater streamline is calculated by Darcy's Law based upon the gradient in total hydraulic head $(\Delta \mathrm{h})$ measured over some distance $(\Delta L)$ as a function of the hydraulic conductivity proportionality constant, $K$ :

$5 \quad v=-K \frac{\partial h}{\partial L}$

The negative sign is employed because flow is in the direction of decreasing water level or water pressure head.

Hydraulic conductivity calculations for the centrifuge permeameter for this study were 10 based on ASTM D6527 (ASTM, 2008) and ASTM D7664 (ASTM, 2010) with a form of Darcy's Law that incorporates the additional driving force within a centrifuge. The ASTM D6527 technique employs similar methods to a standard permeameter test in which the steady state hydraulic conductivity is calculated from the steady state specific discharge through a sample with a free drainage surface for a given hydraulic gradient.

15 Alternative formulations to calculate hydraulic conductivity for different experimental setups and assumptions are provided by a number of authors, such as Nimmo and Mello (1991). For simplicity ASTM D5627 and ASTM D7664 calculate the solution to the equation assuming that the gradient in the pressure head or matric potential (if part of the core is not fully saturated) is negligible when compared to the centrifuge inertial force that is driving flow, i.e.:

$v=K\left[\frac{\omega^{2}}{g}\left(r_{0}-z\right)\right]$

The proportionality term relating flow (which is constant at steady state) and $K$, is the gradient in the centrifuge elevation potential (Nimmo and Mello, 1991), or the gradient in centrifuge "elevation head" (Zornberg and McCartney, 2010) that is due to the centrifuge inertial force that drives flow in a direction away from the centre of rotation (or 3169
HESSD

11, 3155-3212, 2014

Vertical hydraulic conductivity of a clayey-silt aquitard

W. A. Timms et al.

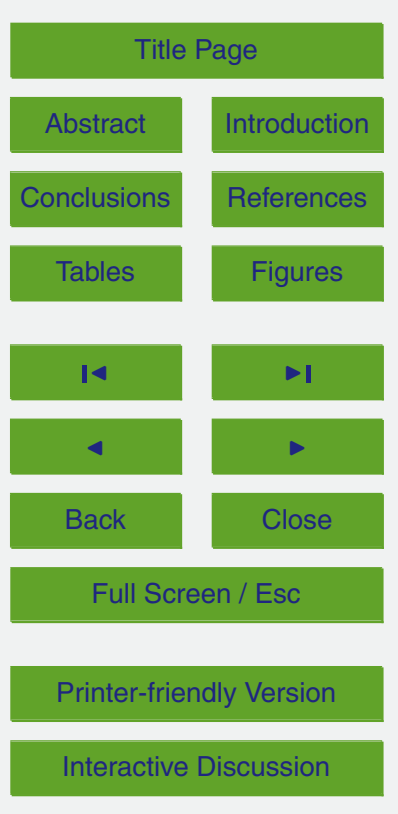

Interactive Discussion 
in the opposite direction to z). ASTM D6527 states that for this assumption to hold, sufficiently high specific discharge and RPM is required. For the SSC-UFA centrifuge permeameter apparatus it is stated that RPM $>300$ is required. For the NCGRT Broadbent CP system, which spins samples at radial distance (to the base of core) of $0.65 \mathrm{~m}$ 5 Given experimental parameters, ASTM D6527 expresses Eq. (8) as:

$K=\frac{0.248 Q}{A r_{\text {mid }}(\mathrm{RPM})^{2}}$

where $K$ is hydraulic conductivity $\left(\mathrm{ms}^{-1}\right), Q$ is fluid flux $\left(\mathrm{mLh}^{-1}\right), \mathrm{RPM}$ is point of the core sample $(\mathrm{cm})$.

It is noted that ASTM D7664 compares steady state centrifuge techniques with various column testing methods at $1 \mathrm{~g}$, with the optional addition of instrumentation to measure the pressure or suction gradient within the core during centrifuge testing. This standard method, following the approach of Zornberg and McCartney (2010), indicates the calculated $K$ is valid for the top third of the core if lower boundary conditions reduce the saturation state (moisture content). However, an added benefit of column testing at accelerated gravity is that effects of boundary conditions are minimized. Furthermore, a ponded influent that maximise the infiltration rate at the top of the core, can be designed at a height above the top of the core to prevent loss of saturation along the core (Nimmo and Mello, 1991).

\subsection{Fluid pressures and total stress}

Fluid pressures and hydraulic gradient through the centrifuge core were determined following the approach of Nimmo and Mello (1991). A bulk density $\rho_{\mathrm{s}}$, of $1.9 \mathrm{~g} \mathrm{~cm}^{-3}$
HESSD

$11,3155-3212,2014$

Vertical hydraulic conductivity of a clayey-silt aquitard

W. A. Timms et al.

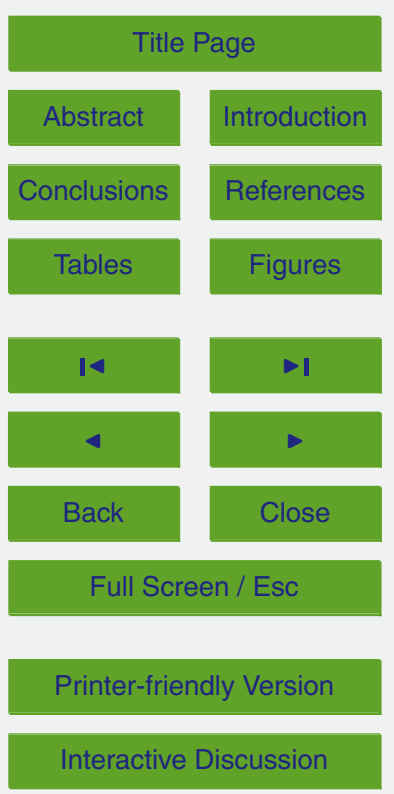


and fluid density $\rho_{w}$, of $1.0 \mathrm{~g} \mathrm{~cm}^{-3}$ was assumed.

$P=\rho_{w} \int_{r 0}^{r} r \omega^{2} d r$

where $P$ is total fluid pressure $(\mathrm{kPa}), \rho_{w}$ is the fluid density $\left(\mathrm{g} \mathrm{cm}^{-3}\right), r$ is the radius 5 of rotation $(\mathrm{cm})$, and $\omega$ is the angular velocity $\left(\mathrm{s}^{-1}\right)$. The total stress was determined through the centrifuge core following

$S=\rho_{\mathrm{s}} \int_{r 0}^{r} r \omega^{2} d r$

where $S$ is total stress $(\mathrm{kPa}), \rho_{\mathrm{s}}$ is the saturated core density $\left(\mathrm{g} \mathrm{cm}^{-3}\right), g$ is gravitational acceleration. The effective stress was calculated as the difference between total stress and fluid pressure. An increase in effective stress associated with decreased fluid pressures near the base of the free draining core may cause consolidation of the core matrix near the boundary.

The total stress applied to the core, relative to in situ stress, may affect the porosity of the core sample, depending on the stress history. In situ stress of the cores at the depth of sampling were estimated on the assumption that the overlaying formations were fully saturated and of a similar density to the supplied core samples:

$$
S_{\text {in situ }}=\rho_{\mathrm{s}} d g
$$

20 where $S_{\text {in situ }}$ is estimated stress of the sample under saturated in situ conditions $(\mathrm{Pa})$, $d$ is depth (mb.g.l. surface to the base of the core), $g$ is standard gravity $\left(\mathrm{m} \mathrm{s}^{-2}\right)$ and $\rho_{\mathrm{s}}$ is saturated density of core $\left(\mathrm{kgm}^{-3}\right)$.

The driving forces for fluid flow, centrifugal force and hydraulic head gradient (stationary centrifuge at $1 \mathrm{~g}$ ) were calculated at $0.005 \mathrm{~m}$ increments through the core. The

Vertical hydraulic conductivity of a clayey-silt aquitard

W. A. Timms et al.

Title Page

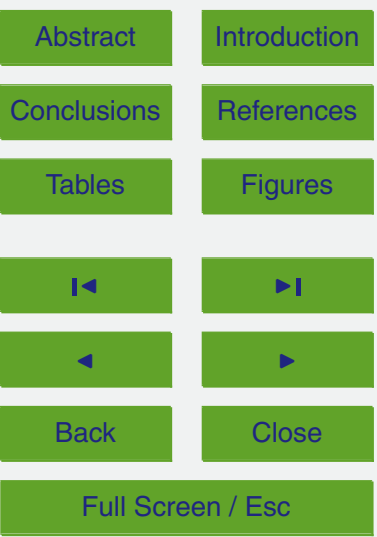

Printer-friendly Version

Interactive Discussion 
fluid flow potential due to the centrifuge $\left(\omega^{2} r\right)$ and fluid head gradient $(\Delta h / \Delta L)$ if the core sample was at $1 g$ were then compared as dimensionless numbers.

\section{Study sites and sampling}

\subsection{Overview of study sites}

5 Semi-consolidated sediment cores were obtained from three sites in the Australia's Murray-Darling Basin, in the Upper Mooki subcatchment of the Namoi catchment (Fig. 3). Groundwater is extracted in this area for irrigation and town water supplies, with drawdowns of more than $10 \mathrm{~m}$ over 30 years. Due to the heterogeneity of mixed sediments, that were previously assumed to be homogenous, high permeability sediments, it can take years or decades for the impact of groundwater withdrawal to be transmitted through the sediments (Kelly et al., 2013). Core drilling was completed at three research sites including Cattle Lane $(C L)$, located south of the town of Caroona, the Breeza farm (BF) operated by the NSW Department of Primary Industries, southeast of Gunnedah, and Norman's Road (NR), east-southeast of Gunnedah.

Clayey silt sediments at the Cattle Lane site are approximately $30 \mathrm{~m}$ thick (Timms and Acworth, 2005) and extend throughout the valley (Wiesner and Acworth, 1999), as shown by numerous CCPT (conductivity cone penetrometer) profiles. The porewater salinity profile at the site, increasing from 10-30 m depth through the clay is consistent with a diffusion dominated transport over thousands of years (Timms and Acworth, 2006). The saturated zone fluctuates between the ground surface and approximately $2 \mathrm{~m}$ depth in response to rainfall events, while water levels in the confined gravel aquifer at $>50 \mathrm{~m}$ depth display a delayed and dampened response to the same rainfall events. There is no groundwater extraction for irrigation from this aquifer in the vicinity of the site, and the valley has had artificial drainage channels constructed to prevent ponding
HESSD

11, 3155-3212, 2014

Vertical hydraulic conductivity of a clayey-silt aquitard

W. A. Timms et al.

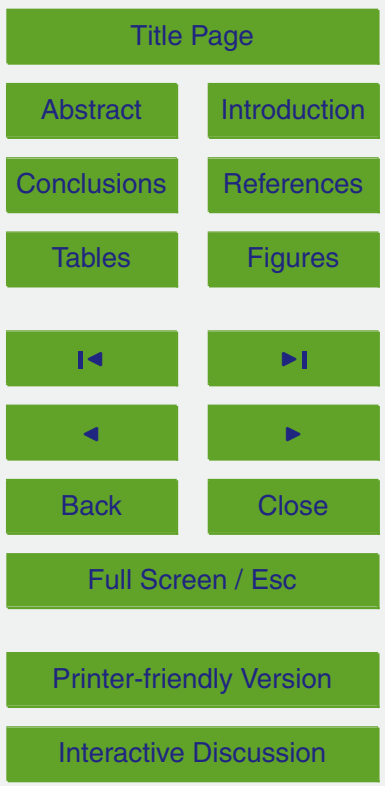


Sediments at the Breeza farm and Norman's Road site are relatively heterogeneous, with mixed sandy, clayey sand, and clayey-silt alluvium overlying a semi-confined aquifer. The saturated zone is approximately 18 to $20 \mathrm{~m}$ below surface and extraction for flood irrigation of crops causes large fluctuations in groundwater levels in the 5 confined aquifers at $>50 \mathrm{~m}$ depth. Hydrogeological and hydrochemical evidence indicate a leaky aquifer-aquitard system (Acworth and Timms, 2009), with the variability in groundwater level responses controlled by a fining upward alluvial sequence (Guinea et al., 2014). At the Norman's Road site, highly saline porewater in the clayey silt near the surface appear to have leached into the underlying aquifer, causing a significant increase in salinity of the aquifer (Badenhop and Timms, 2012).

\subsection{Drilling and core sampling}

Equipment and procedures for coring were compliant with AS 1289.1.1.3 to obtain samples as undisturbed as possible. A rotary drilling rig equipped with Triefus triple core barrels, lined with seamless clear PET, was used in push coring mode. Local creek water was used as a drilling fluid and casing was used to stabilise the hole behind the push core barrel such that drilling fluid additives were not required. The holes were therefore fully cased to the maximum depth of push core drilling at up to $40 \mathrm{mb}$.g.l.

The non-rotating core barrel was forced into the formation whilst a rotating device on the outside of the tube removes the cuttings as the barrel was advanced. The cutting 20 edge of the non-rotating sample tube projects several millimetres beyond the rotary cutters. The thin walled core barrel complied with the standard for undisturbed sampling, with an area ratio of less than $25 \%$ prescribed by AS 1289.1.1.3 for an open drive sampler. The area ratio of $16 \%$ was based on a core barrel design with an external diameter of $110 \mathrm{~mm}$ and internal diameter of $101 \mathrm{~mm}$ (C size). The $1.5 \mathrm{~m}$ length

core barrel was a composite open sampling system with a core nose screwed on the base that included a bevelled end to cut the core as the barrel was pushed into the formation. After the core was extracted from the ground, an air supply was connected
HESSD

Vertical hydraulic conductivity of a clayey-silt aquitard

W. A. Timms et al.

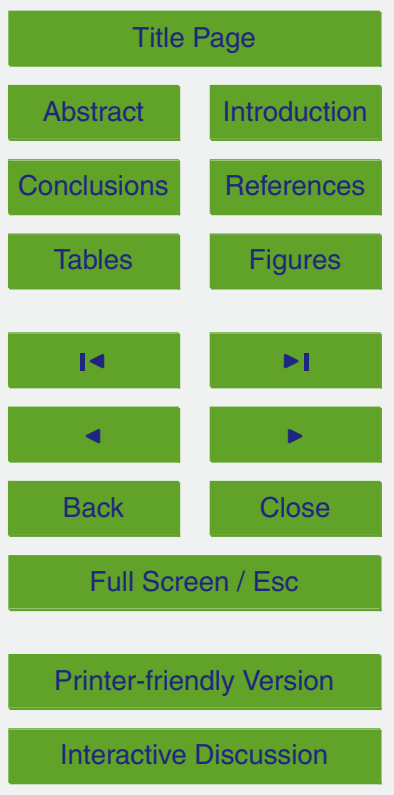


to the top of the core barrel to slide the core out of the barrel whilst retained in the clear PET liner without rotation, distortion or compression.

The cores contained within PET liners in this minimally disturbed state were transferred directly from the core barrels to a cool room on site, and thence to a laboratory $5 \mathrm{cool}$ room, reducing the potential for moisture loss. Semi-consolidated clay cores were selected from below the saturated zone for CP tests, at depths up to $40 \mathrm{mb}$.g.I. Sediment core samples of lengths between $50-100 \mathrm{~mm}$ were prepared for CP testing.

The preferred method for preservation of drill core was double plastic bagging of core sections using a food vacuum sealer, and storage in a cool room at approximately $10 \quad 4^{\circ} \mathrm{C}$. Alternatively, core within PET core barrel liners were trimmed of air or fluid filled excess liner immediately after drilling, sealed with plastic tape, and stored in a cool room. Sections of cores, particularly at the nose end, that appeared to be damaged or disturbed were excluded from permeability or bulk density testing.

After coring, the holes were completed as monitoring piezometers and the casing 15 was jacked out. The piezometers were constructed of screwed sections of $50 \mathrm{~mm}$ PVC casing with 0-ring seals, with a $1.5 \mathrm{~m}$ machine slotted screen packed with pea-sized washed gravel. The annulus was then filled with a bentonite seal, backfilled to the surface and completed with a steel casing monument and cement monument pad.

\subsection{Groundwater sampling for influent}

20 Fluid for permeability testing (influent) should be taken from the formation at the same depth as the core, or if the limitations of sampling from aquitard strata preclude this, influent water chemistry can be synthesized to approximate known ionic strength, $\mathrm{Na} / \mathrm{Ca}$ ratio and $\mathrm{pH}$ of formation porewater. In this study, groundwater from piezometers at a similar depth to the core was obtained using standard groundwater quality sampling 25 techniques (Sundaram et al., 2009). A $240 \mathrm{~V}$ electric submersible pump (GRUNDFOS MP1) and a surface flow cell were used to obtain representative samples after purging stagnant water to achieve constant field measurements of electrical conductivity and other parameters (unpublished data).

Vertical hydraulic conductivity of a clayey-silt aquitard

W. A. Timms et al.

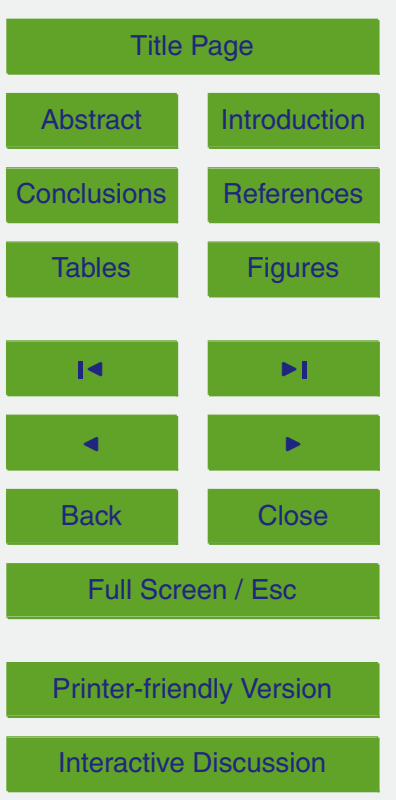




\subsection{Site characterisation using electrical resistivity tomography}

Electrical resistivity tomography indicates subsurface heterogeneity based on spatial variability of bulk conductivity (Acworth, 1999). An ABEM terrameter LS was used with electrodes in the ground at $5 \mathrm{~m}$ spacing over $240 \mathrm{~m}$ length transects. The depth of pen-

5 etration was approximately $30 \mathrm{mb}$ b. .l. The data was inverted using RES2DINV software (Loke, 2001) to provide a model of true resistivity. This paper focuses on a 2-D tomograph model from the CL site for comparison with in situ and laboratory permeability methods.

\section{Experimental setup and procedures}

\section{5.1 Core index testing and $1 \mathrm{~g}$ column permeameter tests}

The moisture content and bulk density of cores was measured on the cores at the drill site using methods adapted from AS (1991) methods AS 1289.2.1.1 and AS 1289.5.3.2 respectively. Blind permeability tests were carried out by an independent laboratory, who adapted a constant/falling head method (AS 1289 6.7.3/5.1.1) with methods from

15 Head (1988). A sample diameter of $45.1 \mathrm{~mm}$ and length $61.83 \mathrm{~mm}$ was used, and a confining pressure of $150 \mathrm{kPa}$ and back pressure of $50 \mathrm{kPa}$ was applied, providing a vertical uniaxial stress of $100 \mathrm{kPa}$. The test time was 2500 to $6000 \mathrm{~min}$ (40 to $100 \mathrm{~h}$ ). Deionised water was used as the influent.

\subsection{Preparation of cores for centrifuge permeameter testing}

20 Subsamples of cores for testing in the centrifuge permeameter were of the following dimensions: $100 \mathrm{~mm}$ diameter $C$ size core, and a length of $50-100 \mathrm{~mm}$. The CP is capable of testing a maximum sample length of $200 \mathrm{~mm}$. Two independent methods were used to mount the porous samples in the liner, depending on the diameter of the core and the degree of consolidation. For unconsolidated cores in this study, a core
HESSD

$11,3155-3212,2014$

Vertical hydraulic conductivity of a clayey-silt aquitard

W. A. Timms et al.

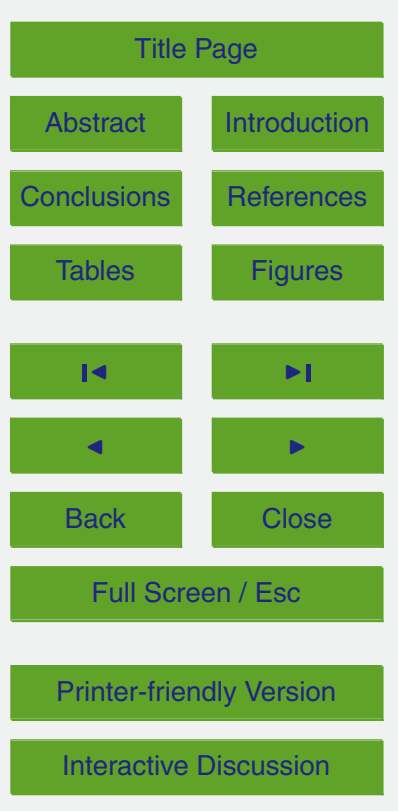

Interactive Discussion 
extruder designed and built at UNSW was used to simultaneously trim and insert the core directly from the PET drill core liners into the acrylic liner for testing. The clay core extruder specifications include 5 precision cutting blades for a $100 \mathrm{~mm}$ diameter cut core and a motor drive piston. The resulting close fit of clay core within the liner 5 ensured that a self-seal was observed to form within minutes of introducing the influent solution. Leakage along the liner interface was readily identifiable by anomalous flow rate several orders of magnitude higher than the steady state flow $K_{\mathrm{v}}$ value. Based on comparisons of flow rates through the drainage hole described in Sect. 5.4, the swelling that occurred to self-seal the core was estimated at $<0.02 \%$ of the crosssectional area of the core, equivalent to seal an annulus of $\sim 0.01 \mathrm{~mm}$.

Given the relatively shallow depth of these cores, and the semi-consolidated status, the maximum $g$-level in the centrifuge was limited to prevent structural changes in the core matrix. To minimise changes in porosity during testing was similar to in situ, the $g$-level and the weight of ponded fluid on the cores were therefore designed to ensure

that total stress was less than estimated in situ stress at the depth from which the core was drilled. In addition to this procedure for seal-sealing cores, techniques described by Bouzalakos et al. (2013) and Timms et al. (2014) are used to seal consolidated rock core, alternative core sizes and geometries (e.g. half core cylinders) into these same acrylic liners using resin and potting rings.

\subsection{Preliminary core testing under vacuum}

To ensure that core was tested under saturated conditions, realistic of in situ conditions, drill core was adequately preserved, stored and set on a vacuum plate prior to centrifuge testing. The preferred system for preservation of drill core was double plastic bagging of core sections using a food vacuum sealer, and storage in a cool room at approximately $4^{\circ} \mathrm{C}$. Alternatively, core within PET core barrel liners were trimmed of air or fluid filled excess liner immediately after drilling, sealed with plastic tape, and stored in a cool room. Storage of cores in open core trays subjected to varying temperature conditions was considered less than ideal.

\section{HESSD}

11, 3155-3212, 2014

\section{Vertical hydraulic conductivity of a clayey-silt aquitard \\ W. A. Timms et al.}

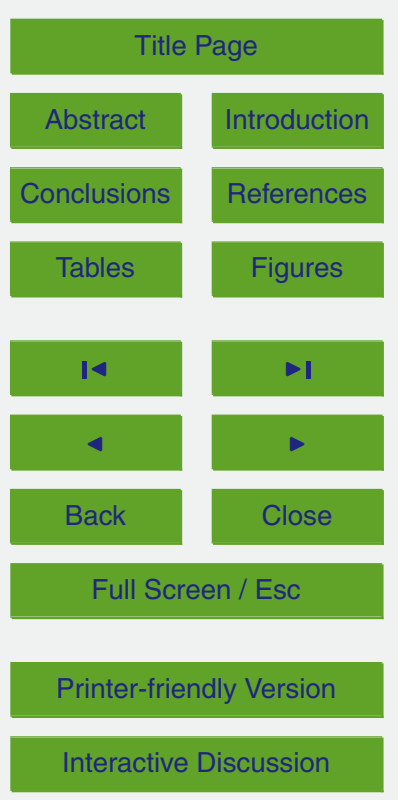


A vacuum plate system for core samples was designed and used for two purposes: maximising the moisture content of samples and testing for rapid leaks of core samples that were prepared in acrylic liners in preparation for CP testing. The vacuum plate device was designed to fit the $\mathrm{CP}$ liners containing the cores, drawing ponded influent 5 from the top to the base of the cores using a standard laboratory vacuum pump at 1 bar of negative pressure. After 12 to $48 \mathrm{~h}$, or upon effluent flow from the base, the acrylic liners containing the prepared cores were then transferred directly to the $\mathrm{CP}$ module without disturbing the sample. Furthermore, the moisture content and degree of saturation was monitoring by weight change of the permeameters during testing, 10 and direct moisture tests of samples before and after CP testing.

\subsection{Centrifuge permeameter flow systems and instrumentation}

In addition to the Broadbent CP module, some unique systems were developed as part of this study. Influent was fed from a pair of burettes located next to the centrifuge via a pair of custom designed low voltage peristaltic pumps mounted either on the centrifuge beam, or outside the centrifuge and through the low flow rotary union described in Sect. 2.5. The peristaltic pumps can be operated either as zero/maximum flow to a set level, or at a variable flow rate of $0.001-150 \mathrm{mLh}^{-1}$. Manual burette measurements to a resolution of $0.1 \mathrm{~mL}$ were used to verify the pump rates.

A PC with LABVIEW software is used for data logging and control of the influent 20 pumping system, originally connected via an Ethernet Optic Rotary Joint (FORJ) that was subsequently replaced by a wireless system. A new data acquisition module (DAS) was designed and constructed with 7 data channels per module, including for influent level monitoring, pressure/load and temperature. A Zigbee based wireless hub was fixed on the centrifuge beam for data transfer from the acquisition modules to a Zigbee 25 wireless modem outside the centrifuge. Low voltage power to the DAS is transferred to the centrifuge beam via slip rings described by Broadbent (2011).

Each permeameter assembly includes a newly designed reservoir insert (see Fig. 4a and b) and employs a pair of custom designed carbon fibre rod electrical conductivity
HESSD

11, 3155-3212, 2014

Vertical hydraulic conductivity of a clayey-silt aquitard

W. A. Timms et al.

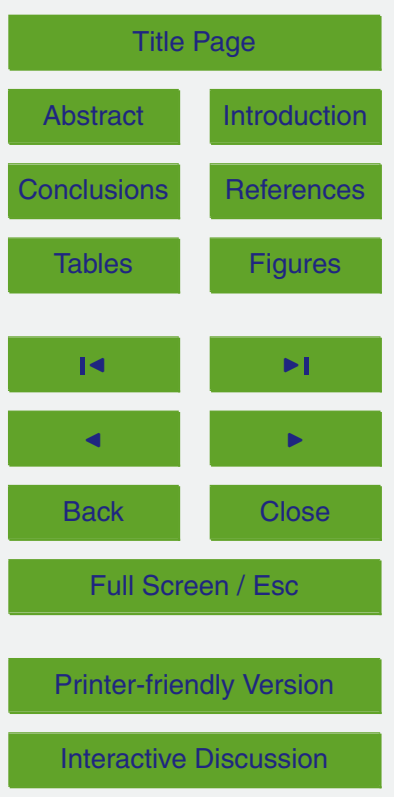


(EC) electrodes to detect the influent reservoir head to an accuracy of $0.1 \mathrm{~mm}$. The head of influent on the core is typically set to maintain a constant head of influent 20 to $100 \mathrm{~mm}$ above the core sample by selection of electrodes of specific length and is therefore maintained at a constant head during $K$ testing. The electrodes protrude 5 through a pluviator cap into the influent reservoir and when the reservoir is depleted a decrease in EC is detected and transmitted back to the PC. The corresponding peristaltic pump is then switched on to automatically pump fluid back into the reservoir. Carbon fibre rod (1 $\mathrm{mm}$ diameter) was selected as the electrode material due to its high tensile strength, low mass, high electrical conductivity and its resistance to corro10 sion.

The permeameter is also equipped with effluent reservoir capacity which is connected to the sample via a drainage plate. In order to allow homogenous flow of fluid from the sample surface into the effluent reservoir the drainage plate is lined with one $1 \mathrm{~mm}$ thick A14 Geofabrics Bidim geofabric filter (110 micron, and permeability of $33 \mathrm{~m} \mathrm{~s}^{-1}$; AS3706.9-01; Geofabrics, 2009) and one Whatman 5 Qualitative filter paper. The hydraulic conductivity of the drainage plate through a drainage hole of $2 \mathrm{~mm}$ diameter was independently measured to ensure that there was no impedance to free drainage. The average permeability $>10$ tests of the drainage plate was $\sim 10^{-5} \mathrm{~ms}^{-1}$ (unpublished data), which is typically a factor of 1000 higher than low permeability core 20 samples.

Effluent is extracted via a syringe or peristaltic pump through a "U" shaped tube that connects to the base of the effluent reservoir (Fig. 4b). The concave dish base of the effluent reservoir has a volume of $\sim 30 \mathrm{~mL}$. This system, designed by UNSW specifically for these studies, enables samples to be extracted without the need for the permeameters to be taken off the beam, thereby alleviating safety risks in lifting heavy permeameters, and reduces the stop time required for a sampling event during centrifuge flight to less than $5 \mathrm{~min}$.

An air vent, located at the top of the reservoir near the lower end of the drainage plate, connects the reservoir to the outside of the permeameter, thereby maintaining
HESSD

11, 3155-3212, 2014

Vertical hydraulic conductivity of a clayey-silt aquitard

W. A. Timms et al.

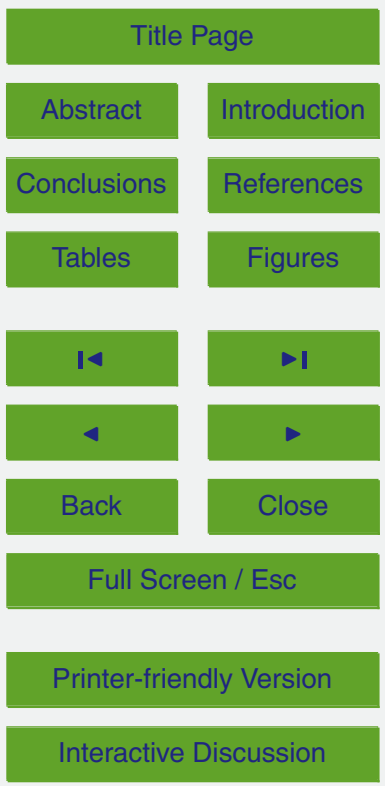


a zero pressure outflow boundary. The free drainage boundary condition is different from other centrifuge flow setups and is important for subsequent interpretation of flow processes during.

\subsection{Centrifuge permeameter test operation}

5 The $K$ value is based on flow rate, flow area, radius and RPM, although the method was adapted from a UFA centrifuge to this CP system (Sect. 3.2). Importantly, both testing systems are for steady state flow with free drainage due to zero pressure at the base of the core.

Two core samples were balanced to the nearest $100 \mathrm{~g}$ and tested simultaneously at either end of the centrifuge beam. The centrifuge permeameter was operated at $10 \mathrm{~g}$ for 20-30 min, and if no rapid flows due to leakage were detected, is gradually increased to $20 \mathrm{~g}, 40 \mathrm{~g}$ and so on, until the maximum total stress on the core approaches the estimated in situ stresses of the material at its the depth in the formation from which it was cored. It is also important to ensure that effective stress (Sect. 3.3) remains acceptable, as dynamic fluid pressures during testing could cause consolidation of the core matrix, as discussed in Sect. 6.7. Influent volume was measured using both a calibrated continuous time record of pump rotations, and manual burette measurements, and compared to effluent volume until a steady state flow of $\pm 10 \%$ change between measurements was achieved. Section 6.6 discusses the uncertainty of the measured data in more detail.

\section{Results and discussion}

\subsection{Core index properties}

Index properties for five representative cores are provided in Table 3, indicating that these cores were typically silty clay, confirmed by the $D_{50}$ values of $<0.002 \mathrm{~mm}$ that

differentiates clay from silt, except for the sandy clay core. The dominance of silty over
HESSD

11, 3155-3212, 2014

Vertical hydraulic conductivity of a clayey-silt aquitard

W. A. Timms et al.

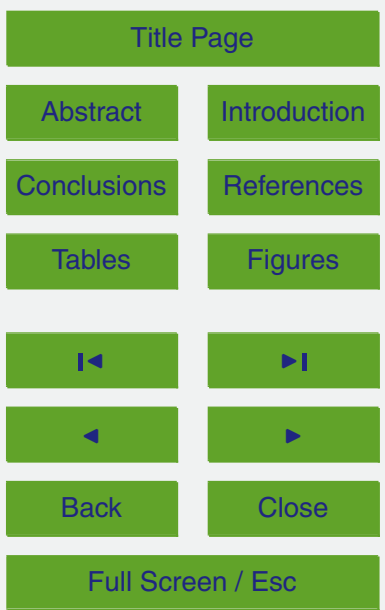

Printer-friendly Version

Interactive Discussion 
clay is an important characteristic of this formation, with clay mineralogy dominated by smectite (Timms and Acworth, 2005; Acworth and Timms, 2009).

Moisture content varied from 24.7 to $36.4 \%$ by weight, and was consistent with site measured data on the core (unpublished data), although not all the cores were 5 fully saturated as received by the external laboratory. Bulk density varied from 1.71 to $1.88 \mathrm{~g} \mathrm{~cm}^{-3}$ and particle density from 2.47 to $2.58 \mathrm{~g} \mathrm{~cm}^{-3}$.

\subsection{Centrifuge permeameter and $1 \mathrm{~g}$ column tests of cores}

The $K_{\mathrm{v}}$ of cores tested in the CP module (Table 4) varied from $3.5 \times 10^{-7}$ to $1.0 \times$ $10^{-9} \mathrm{~ms}^{-1}(n=14)$. These results were generally higher than $K_{\mathrm{v}}$ results of $2 \times 10^{-9}$ to

$104.9 \times 10^{-11} \mathrm{~ms}^{-1}(n=7)$, using column tests (Table 5) at $1 \mathrm{~g}$. Accelerations up to $80 \mathrm{~g}$ were applied during CP testing of semi-consolidated sediment cores and were more typically limited to $30-40 \mathrm{~g}$, with test times up to five times faster than by column tests at $1 \mathrm{~g}$. The possible reasons for the higher $K$ results and reduced testing time for CP testing compared with $1 \mathrm{~g}$ column tests are considered in this section.

15 Figure 5 shows the measured influent and effluent rates during a typical CP test as the $g$-level is gradually increased, and the calculated $K_{\mathrm{v}}$ values. The $g$-levels were gradually stepped upwards to allow time for excess pore fluid pressures to equilibrate through the core in a sequence that was designed to verify flow rate variability $(10,20$, $40,60,80$ and back to $60 \mathrm{~g}$ ). Steady state flow (influent rate equal to effluent rate with no significant change over time) was achieved at $\sim 20 \mathrm{~h}$, with some anomalous data earlier in the test (Fig. 5). However, a lower $K_{\mathrm{v}}$ value was observed over $>12 \mathrm{~h}$ overnight, then values measured over $\sim 1 \mathrm{~h}$ intervals during the day with frequent stops of several minutes duration to measure the effluent volume, the later time interval measurement considered to be more realistic. Further experimentation and numerical modelling is required to adequately explain this discrepancy with may be associated with evaporative losses over longer time periods of flow measurement or other transient processes within the system.

\section{HESSD}

$11,3155-3212,2014$

Vertical hydraulic conductivity of a clayey-silt aquitard

W. A. Timms et al.

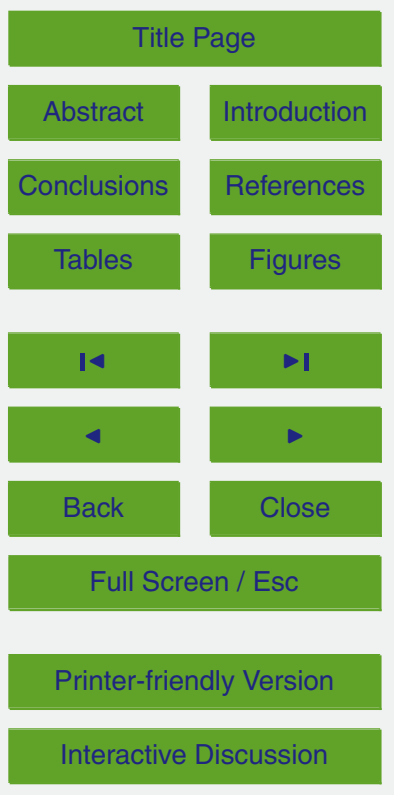


Anomalous flow via preferential pathways could be readily identified by a flow rate several orders of magnitude greater than otherwise observed. Anomalous flow was often observed along the interface of the cores and the liner during the early minutes of a test as sealing occurred at steady state conditions were established. On one occa5 sion, a failure occurred in the core during testing, with a preferential flow path occurring through the matrix, which at accelerated gravity causes very fast flow that is easily detected.

$K_{\mathrm{v}}$ values for cores from the NR and BF sites were significantly more variable (over $10^{-9}$ to $10^{-7} \mathrm{~ms}^{-1}$ ) than for the CL site (within $10^{-9} \mathrm{~m} \mathrm{~s}^{-1}$ ). These findings reflect the 10 greater heterogeneity of alluvial sediments at the northern sites (NR and BF), compared with the clayey-silt deposit at the southern CL site. Based on the dataset currently available for each site, there did not appear to be any significant $K_{\mathrm{v}}$ trend with depth, except at the CL site, with a possible decrease of $K_{\mathrm{v}}$ by a factor of 3 with depth increasing from 11 to $28 \mathrm{mb}$.g.l. Further testing is in progress to better identify any 15 spatially significant trends in $K_{\mathrm{v}}$.

$K_{\mathrm{v}}$ results obtained from the same CP from these three sites were generally higher than $K_{\mathrm{v}}$ results from another alluvial system in the western Murray-Darling Basin (unpublished data), and significantly higher than $K_{\mathrm{v}}$ for consolidated rock cores tested in this system (Bouzalakos et al., 2013). At an undisclosed site in the western Murray20 Darling Basin, the hydraulic conductivity of twelve (12) drill cores ranged from $1 \times 10^{-11}$ to $6 \times 10^{-6} \mathrm{~ms}^{-1}$, while five (5) cores were $\leq 10^{-12} \mathrm{~ms}^{-1}$ (unpublished data). The relatively low $g$-levels, compared to rock core testing (Bouzalakos et al., 2013), were necessary for the shallow and semi-consolidated nature of the clayey-silt cores. In fact, steady state flow was achieved at low $g$-levels for $K_{\mathrm{v}}$ values that were at least 100 times

The uncertainty of reporting results to two significant digits for $K_{\mathrm{v}}$ as low as $10^{-9} \mathrm{~m} \mathrm{~s}^{-1}$ is further discussed in Sect. 6.6. In contrast, $K_{\mathrm{v}}$ results from an independent laboratory were reported to 3 significant digits for the first batch of samples tested, and

HESSD

$11,3155-3212,2014$

Vertical hydraulic conductivity of a clayey-silt aquitard

W. A. Timms et al.

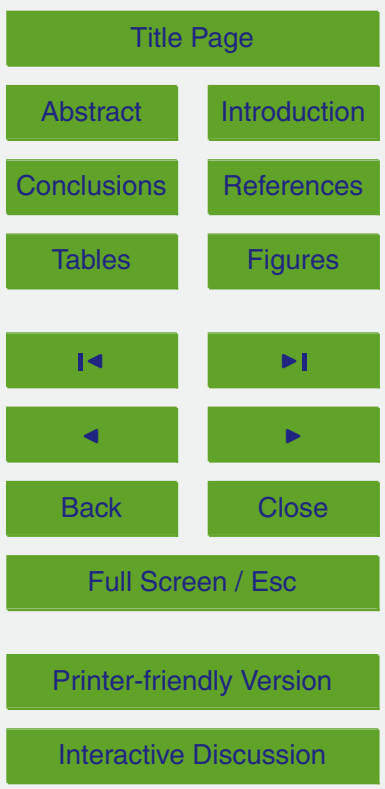


1 significant digits for a subsequent batch of samples, although the range of $K_{\mathrm{v}}$ values were similar for both batches.

The reduced test times of CP testing may be attributed to the reduced time required to achieve steady state flow with centrifugal forces driving flow. Alternatively, the time 5 required for $1 \mathrm{~g}$ column testing may have increased due to fluid-solid interactions that reduced infiltration rates into the cores (10 to 100 lower $K_{\mathrm{v}}$ result for $1 \mathrm{~g}$ column tests compared with CP tests). It is known that decreased ionic strength of influent (e.g. deionized water) causes a linear decrease in permeability, and that the relative concentrations of sodium and calcium can affect permeability due to swelling and inter10 layer interactions (e.g. Shackelford et al., 2010; Ahn and Jo, 2009). It is also possible that differences in $K$ values from laboratory testing methods can also be attributed to differences in test setup and stress changes that occur as discussed in Sect. 6.7. The centrifuge permeameter uses a larger core size $(100 \mathrm{~mm}$ diameter $)$ and groundwater sampled near the depth of the core, whereas the $1 \mathrm{~g}$ column uses a small core diameter 15 (45 mm diameter) and deionized water as an influent.

$\mathrm{CP}$ testing was relatively rapid, with an average of less than $16 \mathrm{~h}$ ( 2 to $24 \mathrm{~h}$ ) required for steady state flow CP, compared with an average of $79 \mathrm{~h}$ (48 to $100 \mathrm{~h}$ ) for $1 \mathrm{~g}$ column testing. In addition, an extended test of $830 \mathrm{~h}$ in the CP (unpublished data) verified that no significant changes occurred over extended testing periods. The CP technique can therefore reduce average testing time to $\sim 20 \%$ of the time that would be required in $1 \mathrm{~g}$ laboratory testing systems, similar to the reduced time requirement of centrifuge methods for unsaturated hydraulic conductivity functions compared with $1 \mathrm{~g}$ column tests ASTM (2010). The relative time advantage of testing cores at accelerated gravity may be greater at lower $K_{\mathrm{v}}$, due to the increased time required to establish steady state flow conditions. This could be advantageous for longer experiments of contaminant transport that requires several pore volumes of steady state flow.

Vertical hydraulic conductivity of a clayey-silt aquitard

W. A. Timms et al.

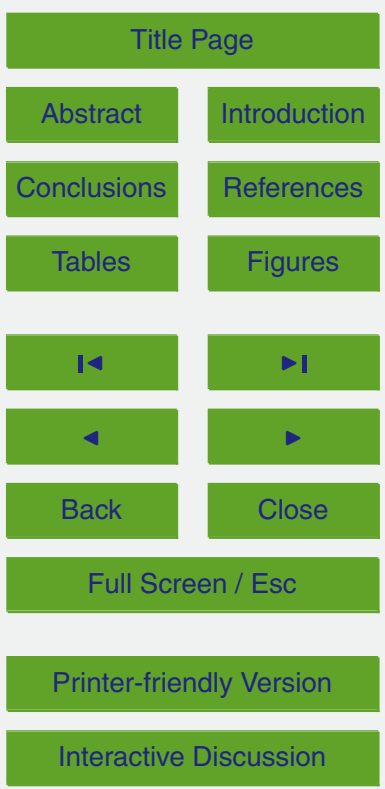




\subsection{Validation of results with in situ $K_{\mathrm{v}}$ estimates}

There is a general lack of in situ $K_{v}$ measurements in this groundwater system. There have been no reported aquifer pump tests in the alluvial aquifer in this area, other than observations of the effects of irrigation bores over various spatial and temporal scales.

Vertical hydraulic conductivity $\left(K_{\mathrm{v}}\right)$ of the clayey-silt at the Cattle Lane site derived from observed amplitude and phase changes, resulted in an average value of $2.8 \times 10^{-9} \mathrm{~ms}^{-1}$ (Timms and Acworth, 2005). Five major rainfall events occurred during detailed pore pressure monitoring in five piezometers on an hourly or 6 hourly basis over four years. These data were verified and augmented by manual groundwater level 10 measurements. The phase lag at the base of the clay varied between 49 and 72 days. The phase lag pore pressure analysis resulted in a $K_{\mathrm{v}}$ value of $1.6 \times 10^{-9} \mathrm{~ms}^{-1}$, while the change in amplitude over a vertical clay sequence of $18 \mathrm{~m}$ (from a $17 \mathrm{~m}$ depth piezometer to the inferred base of the aquitard at $35 \mathrm{~m}$ depth) resulted in a $K_{\mathrm{v}}$ value of $4.0 \times 10^{-9} \mathrm{~m} \mathrm{~s}^{-1}$. The average value of $K_{\mathrm{v}}$ from these two estimates is $2.8 \times 10^{-9} \mathrm{~m} \mathrm{~s}^{-1}$ 15 which is possibly indicative at formation scale in this area, given the thick and extensive lateral extent as discussed below.

The reliability of harmonic analysis related methods may be compromised by specific storage measurements. Jiang et al. (2013) relied on indirect specific storage values derived from downhole sonic and density log data from boreholes in the region, while

20 Timms and Acworth (2005) calculated specific storage from barometric and loading responses that were recorded in the same groundwater level data set and boreholes that were used for harmonic analysis.

With the advantage of robust estimates for specific storage in this study, the similarity of $K_{\mathrm{v}}$ measurements different scales at the CL site (Fig. 6) indicates that in this 25 part of the alluvial deposit, $K$ is independent of the scale of measurement and that no hydraulically active fractures or vertical flowpaths affected the data. As discussed further in Sect. 6.8, this finding is consistent with work on argillaceous strata by Neuzil

\section{HESSD}

11, 3155-3212, 2014

Vertical hydraulic conductivity of a clayey-silt aquitard

W. A. Timms et al.

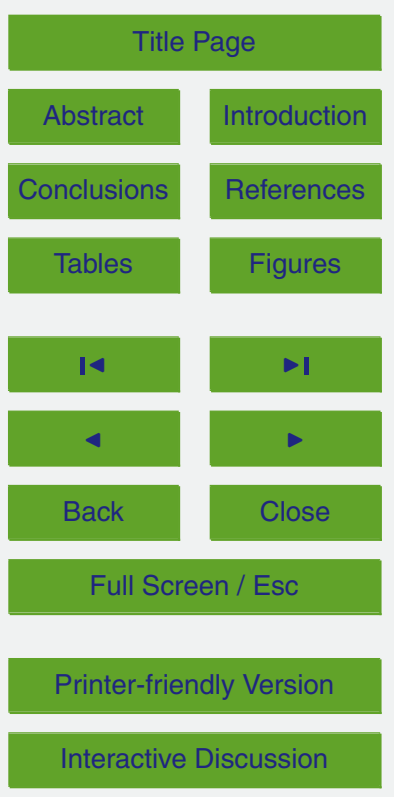


(1994), but contrasts with evidence of scale dependant $K$ values in other groundwater systems.

Electrical resistivity tomography (Fig. 7) at the CL site confirmed the lateral extent of the relatively uniform formation in this area of the catchment. An electrical resistivity 5 tomograph model indicated a homogenous layered system over a $240 \mathrm{~m}$ extent with resistivity increasing with depth to about $10 \mathrm{~m}$ depth, and then is relatively similar to a depth of about $30 \mathrm{~m}$. This confirms a relatively uniform sediment in this area as found by CPT profiling by Wiesner and Acworth (1999).

\subsection{Comparison of results with regional $K_{\mathrm{v}}$ estimates}

10 A regional groundwater flow model developed by McNeilage (2006) with a 2 layer MODFLOW code, determined the dominant source of recharge to be diffuse leakage through the soil (and aquitards) in the Breeza area (Zone 3 groundwater management area). As in typical modelling practice (Barnett et al., 2012), water the aquitard was not explicitly modelled, with water instead transferred from a shallow to a deeper aquifer using 15 a vertical leakance value (units in $d y^{-1}$ ), a model variable that is calculated for each cell of the model.

The calibrated groundwater model indicated that approximately $70 \%$ of the long term average groundwater recharge $\left(11 \mathrm{GLyr}^{-1}\right)$ was attributed to diffuse leakage in this area that included the $\mathrm{CL}$ and NR sites. This volume is equivalent to $20 \mathrm{~mm} \mathrm{yr}^{-1}$, or

20 a $K_{\mathrm{v}}$ of $\sim 6 \times 10^{-10} \mathrm{~m} \mathrm{~s}^{-1}$ assuming a unit vertical hydraulic gradient over an area of approximately $500 \mathrm{~km}^{2}$. The actual $K_{\mathrm{v}}$ or leakance values were not reported. The calibrated leakance values were found to vary over three orders of magnitude across the Breeza area, with relatively high values in isolated area in the south, centre and north. In comparison, the $K_{\mathrm{v}}$ results on clayey-silt cores appear to be higher, but with a similar degree of heterogeneity.

Vertical hydraulic conductivity of a clayey-silt aquitard

W. A. Timms et al.

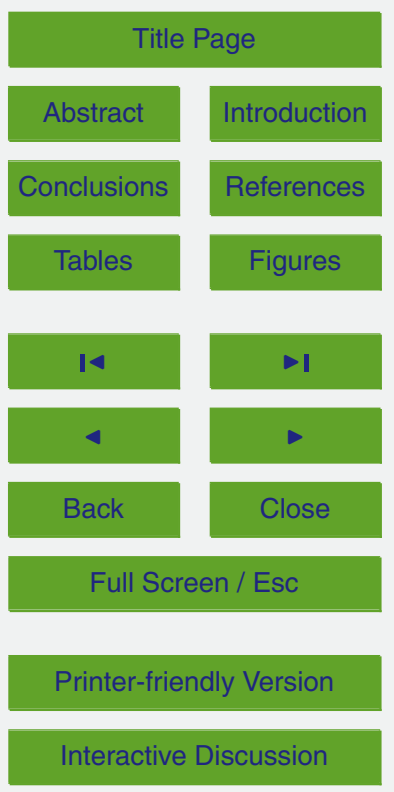




\subsection{Linear flow velocity at natural gradient and accelerated conditions}

To determine if accelerated flow conditions are realistic for hydrogeological environments, the linear flow velocity (apparent flow velocity corrected for porosity) for various CP setups was compared with a theoretical unit gradient, and a typical vertical in situ 5 vertical hydraulic gradient. Figure 8 illustrates concepts for fluid flow at accelerated gravity. The hydrostatic fluid pressure (Eq. 9), measured at a radial position within the core sample, increases with distance from the axis of rotation, continuing into a pressured reservoir boundary, or decreasing to zero at a free drainage boundary. By contrast, the centrifuge inertial (elevation) head decreases with increasing distance from the axis of rotation, as also shown by Nimmo and Mello (1991) and McCartney (2007). It follows that the direction of fluid flow is outwards, in the opposite direction to the axis of rotation. The gradients that drive flow are depicted in Fig. 8b, with the most significant driving force due to centrifugal acceleration. The numerical analysis of fluid pressures that develop during flow and transition to new $g$-levels is beyond the scope 15 of the current study.

In Table 6, an in situ hydraulic gradient of 0.5 is compared with CP setups for $100 \mathrm{~mm}$ and $65 \mathrm{~mm}$ diameter cores of various lengths, for an aquitard material with $K_{\mathrm{v}}$ of $10^{-8} \mathrm{~ms}^{-1}$. The vertical flow rate varies from $0.3 \mathrm{mLh}^{-1}$ under in situ conditions, to $8.5 \mathrm{mLh}^{-1}$ in the CP, such that linear flow velocities remain very low $10^{-8}$ to $10^{-6} \mathrm{~ms}^{-1}$.

20 The flow rate during centrifugation was $\mathrm{N}$ times greater than if a hydraulic gradient of 1 was applied to the core samples at $1 \mathrm{~g}$. This increase in flow rate is consistent with scaling laws for physical modelling (Tan and Scott, 1987), and is greater than would occur within aquitards where the vertical hydraulic gradient is typically less than one. An in situ vertical hydraulic gradient determined from measurements in piezometers that are located above, below and within the aquitard sequence can provide hydraulic gradients that are typically higher than hydraulic gradients for lateral flow.

Steady state flow $K_{\mathrm{v}}$ testing in the CP requires a relatively short testing time, as described in Sect. 6.2, whereas for solute transport experiments, a longer experimental
Vertical hydraulic conductivity of a clayey-silt aquitard

W. A. Timms et al.

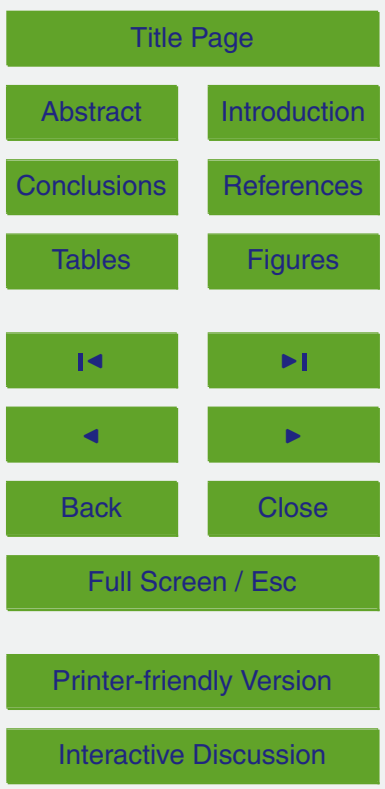


time is required for several pore volumes (PV) of flow. For example, Timms and Hendry (2008) and Timms et al. (2009) describe continuous CP experiments over 90 days to quantify reactive solute transport. The comparisons of time required for one $\mathrm{PV}$ provided in Table 6 illustrate the possible advantages of CP for contaminant flow that 5 may affect the structural integrity of the material.

\subsection{Limits and uncertainties of centrifuge permeameter testing}

$K$ values measured in this study are within the range of applicability of Darcy's Law for laminar flow at accelerated gravity. Flow of fluid through porous media at accelerated gravity was found by Nimmo et al. (1987) to follow Darcy's law for accelerations below the laboratory is $10^{-16} \mathrm{~m} \mathrm{~s}^{-1}$ (equivalent to approximately $10^{-11}$ Darcy, or $10^{-19} \mathrm{~cm}^{2}$ ) in the UFA centrifuge (Conca and Wright, 1998). At accelerated gravity, steady state flow equilibrium is achieved in a time of hours and days, and in situ stresses can be applied to drill core from approximately $<100 \mathrm{~m}$ depth or a total stress of approximately $1 \mathrm{MPa}$ in the Broadbent CP system (without weighting discs).

Hydraulic conductivity data derived from experiments in the centrifuge permeameter include a component of measurement error. The quantified components of the measurement error are: limit of reading for time $\pm 1 \mathrm{~s}$; limit of reading for permeameter (total mass) balance $\pm 0.5 \mathrm{~g}$; limit of reading for high precision (outflow mass) balance $\pm 0.1 \mathrm{~g}$; 20 limit of reading for influent control burette $\pm 0.1 \mathrm{~mL}$; accuracy of automatic influent control system $\pm 0.1 \mathrm{~mL}$; accuracy of influent fluid level monitoring system $\pm 0.2 \mathrm{~mm}$; fluid held by surface tension in effluent reservoir and on reservoir base plate $< \pm 1.0 \mathrm{~mL}$; evaporation from permeameter chambers $<0.3 \mathrm{mmd}^{-1}\left(<2.2 \mathrm{mLdy}^{-1}\right.$ at $\left.875 \mathrm{RPM}\right)$.

Sidewall leakage between the core-sample and wall of the permeameter, and any resin that is required to set the core sample for testing has been quantified and is below the hydraulic conductivity detection limit. The current detection limit of the centrifuge permeameter ranges from $3 \times 10^{-11}$ to $1 \times 10^{-12} \mathrm{~m} \mathrm{~s}^{-1}$ and is controlled by evaporation which increases with increasing centripetal acceleration. For the low levels required

Vertical hydraulic conductivity of a clayey-silt aquitard

W. A. Timms et al.

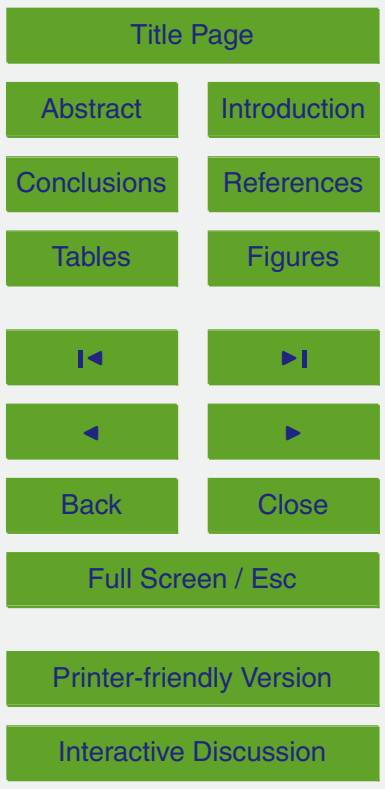


for semi-consolidated clay core, the detection limit was $1 \times 10^{-12} \mathrm{~ms}^{-1}$. For the experimental procedure followed for this study the above volumetric errors translate to an uncertainty in the measurement of $K$ that is typically better than $\pm 15 \%$.

\subsection{Pore fluid pressure and stress conditions during centrifuge permeameter testing}

While the errors that may occur during measurement of $K$ can be defined, whether or not the $K$ value is realistic of in situ conditions depends in part on the magnitude of stress and any structural changes that occur within the core matrix. Consideration of stress regimes is particularly important for semi-consolidated core matrix, and for compressive or swelling materials. In situ stresses can be simulated in both a CP test and $1 \mathrm{~g}$ column test, depending on the core setup capabilities of the testing equipment, and testing design. At the low $g$-levels and stresses required for these relatively shallow semi-consolidated cores, the stress conditions in both tests were similar.

Calculated pore fluid pressure and total stress are shown in Fig. 9 for a $50 \mathrm{~mm}$ length 15 core at $40 \mathrm{~g}$ for the Broadbent CP module, based on Eqs. (9) and (10), in $0.005 \mathrm{~m}$ increments of radius. The effective stress, the difference between the total stress and pore fluid pressures, is evidently highest towards the base of the core, before the effects of a free drainage base (zero pressure) occur within the core. At $40 \mathrm{~g}$, the total stress at the base of the core is $40 \mathrm{kPa}$, or $34 \mathrm{kPa}$ plus $6 \mathrm{kPa}$ of stress at the top of the core assuming a fluid head of $20 \mathrm{~mm}$ ponded on the top of a $50 \mathrm{~mm}$ length of core. At $80 \mathrm{~g}$, the total stress at the base of the core is $74 \mathrm{kPa}$. This is significantly less than the maximum in situ stress for core samples listed in Table 4, calculated using Eq. (11).

During centrifuge testing, effective stress is maximum at the base of the free draining core, where fluid pressure is zero, and thus effective stress is equal to total stress under hydrostatic conditions (no flow). In both testing methods in this study, the total stress was less than estimated in situ stress, however the stress history of the core sample and effective stress dynamics were uncertain. Considering that a stress is necessary
HESSD

$11,3155-3212,2014$

Vertical hydraulic conductivity of a clayey-silt aquitard

W. A. Timms et al.

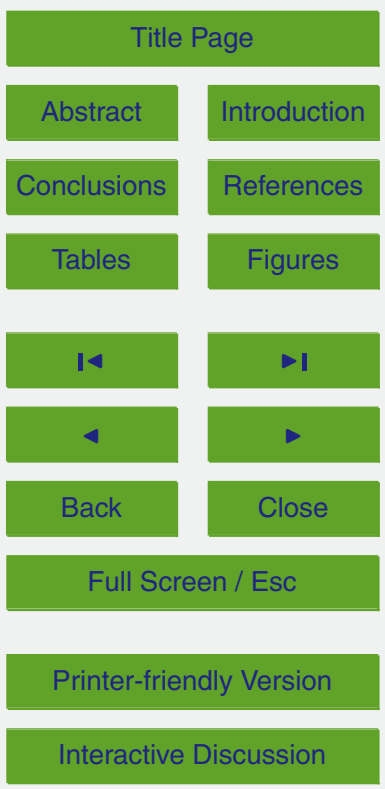


on top of the core to prevent swelling of the core, it appears that the stresses during these tests were likely within an acceptable range to minimise structural changes including swelling and consolidation. However, further attention on these processes, including instrumentation to measure fluid pressures and core matrix changes during 5 testing is required in future studies.

Figure 8b shows the water head gradient of 0.4 (at $1 \mathrm{~g}$ ) compared with the centrifuge "elevation head" gradient or centrifuge inertial force that drives fluid flow within the centrifuge for both the Broadbent CP module and the UFA system at $40 \mathrm{~g}$. As described in Sect. 4.2, the Broadbent CP module achieves a more constant $g$-level over the length 10 of a $50 \mathrm{~mm}$ core than is possible in the smaller UFA system. The centrifuge elevation gradient driving flow is significantly greater than the water head gradient that would occur at $1 \mathrm{~g}$, and is more uniform in the Broadbent CP module (37 to $40 \mathrm{~g}$ ) compared with the UFA system (23 to $40 \mathrm{~g}$ ), or a variation of 7 and $41 \%$ respectively.

These findings confirm previous studies that noted the importance of centrifuge ex15 perimental design to achieve linear stress and pressure gradients. Nakajim and Stadler (2006) found that non-linearity in pore pressure distribution was not significant where the ratio of radius and sample size $(r / L)$ was large. In their study, the $r / L$ ratio was $8(2.0 / 0.25)$. By this criteria it is noted that for the examples given here, the $r / L$ ratio of $130(0.65 / 0.005)$ in the Broadbent CP module is more favourable than for the UFA setup where the $r / L$ ratio of $22(0.11 / 0.005)$. Timms et al. (2003) noted that accurate scaling of physical factors (eg length, time) in the UFA centrifuge was limited by differing acceleration and stress experienced at the top and base of the core. A larger radius centrifuge operated at lower speeds minimises stress gradients within the core, thus minimising the possibility that variable stresses affect the structure of the core sample.

\subsection{Benefits of core scale measurement of aquitard properties}

The natural variability within apparently homogeneous geological media is large (Schulze-Makuch et al., 1999). For example, Neuzil (1994) reported that for similar porosity, hydraulic conductivity commonly varies over three orders of magnitude. When

\section{HESSD}

$11,3155-3212,2014$

Vertical hydraulic conductivity of a clayey-silt aquitard

W. A. Timms et al.

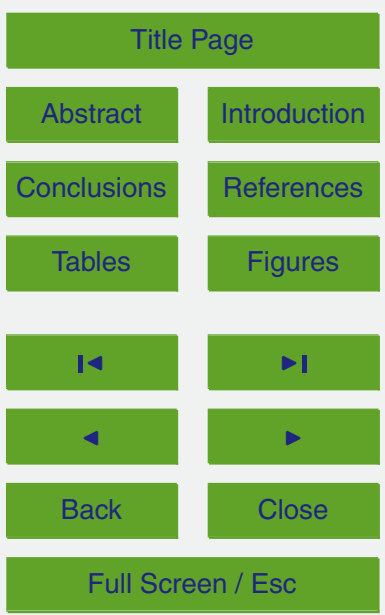

Printer-friendly Version

Interactive Discussion 
parameterising this variability in flow models, predictions of groundwater impacts from aquifer interference activities can exhibit a significant degree of uncertainty. Core scale measurements of aquitard properties provide an opportunity to reduce this uncertainty by providing a likely minimum value of matrix permeability if the cores are drilled, pre5 served, prepared and tested in an appropriate manner as demonstrated in this study.

For argillaceous strata permeability often does not increase with increasing physical scale of testing at least at intermediate scale, indicating that permeability due to fracturing is absent (Neuzil, 1994). In the absence of direct measurement of aquitard permeability there is a real risk that aquitard parameters may be ignored or misrepresented in 10 analyses resulting in a corresponding under-prediction of vertical connectivity via preferential flow paths and/or over-prediction of aquifer storage and transmissivity. This is an especially important consideration in the analysis of aquifer tests that may not have been conducted for sufficient periods of time to identify distant boundary conditions or the characteristic effects of aquitard leakage and/or storage (Neuman and Witherspoon, 1968). In very low permeability strata however, there are practical limitations to pump tests and packer testing below about $10^{-8} \mathrm{~ms}^{-1}$, depending on the equipment and the length of strata that is subject to testing. It is recognised that in many heterogeneous systems that time lags for the propagation of drawdown responses through an aquitard can be significant (Kelly et al., 2013).

Core scale measures of aquitard hydraulic conductivity are an integral component of hydrogeological studies concerning aquifer connectivity. The availability of core scale facies measurements enables the up-scaling of bore log and geophysical data to determine upper and lower hydraulic conductivity bounds for regionally up-scaled aquitard units. Any differences between $K$ values at various scale is important for indicating the possibility of preferential flow through heterogeneous strata or aquitard defects (e.g. faults and fractures). The availability of these bounded estimates helps to constrain the uncertainty analyses conducted on regional groundwater flow models to yield more confident predictions (Gerber and Howard, 2000).

\section{HESSD}

$11,3155-3212,2014$

Vertical hydraulic conductivity of a clayey-silt aquitard

W. A. Timms et al.

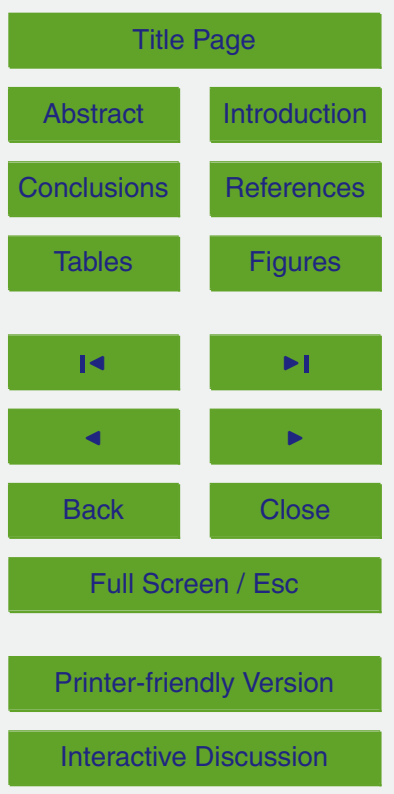


Nevertheless, aquitards are typically excluded from regional groundwater flow models, which rely on hydraulic resistance (leakance) values to transfer water vertically between aquifers (Barnett et al., 2012). However, such an approach is not capable of identifying rapid flow pathways through defects in the aquitards or the release of 5 stored water from an aquitard to an aquifer and cannot resolve the vertical hydraulic head distribution across the aquitard to verify drawdown responses. An aquitard should be subdivided into at least three thinner layers to effectively model transient pressure responses (Barnett et al., 2012). Rather than assigning constant theoretical values for aquitard properties through these multiple layers, a combination of realistic and 10 rapid laboratory measurement and direct in situ measurements may be considered where high risk activities demand improved confidence in conceptual understanding and model predictions.

\section{Conclusions and further work}

Accurate and reliable measurement of the vertical hydraulic conductivity of aquitards 15 is a critical concern for many applications. More realistic numerical flow models are possible to quantify the significance of transient drawdown, the associated release of water into adjacent aquifers over long time periods, and the possibility of preferential flow. However, increasing the complexity of hydro-geochemical models cannot improve confidence in the conceptual model if the original data on aquitard hydraulic properties 20 is inaccurate or absent.

Centrifuge technology can be a powerful tool for hydraulic and geotechnical characterization of low permeability sediments and rocks to augment site and regional scale assessments. The lengthy time required to obtain realistic aquitard hydraulic data is substantially reduced by achieving hydraulic equilibrium under accelerated gravity.

25 Value can be added to the cost of drilling if strata samples are drilled using coring methods with minimal disturbance, preserving the cores to prevent moisture loss, and appropriate preparation and testing of the cores as demonstrated in this study.

\section{HESSD}

Vertical hydraulic conductivity of a clayey-silt aquitard

W. A. Timms et al.

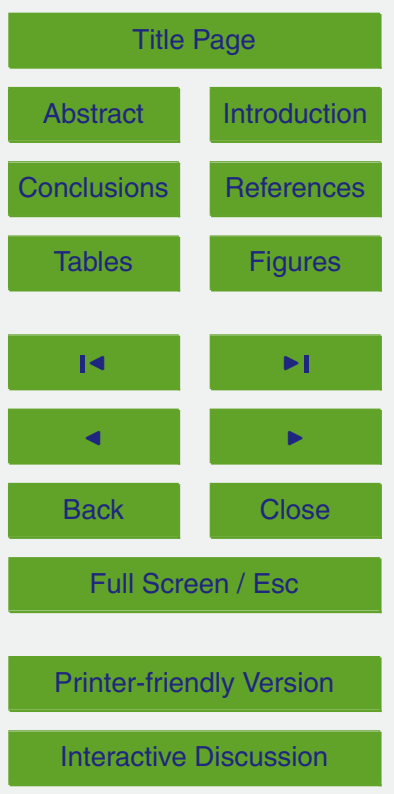


Core tests using formation water or groundwater as an influent with realistic stresses can provide a reliable minimum matrix scale value for evaluating the potential for vertical flow at a larger scale. Any differences between $K$ values at various scale is important for indicating the possibility of preferential flow through heterogeneous strata 5 or aquitard defects (e.g. faults and fractures). $K_{\mathrm{v}}$ results in the order of $10^{-9} \mathrm{~m} \mathrm{~s}^{-1}$ were obtained in $\sim 20 \%$ of the time required for $1 \mathrm{~g}$ column permeameter tests. The $K_{\mathrm{v}}$ values were successfully verified with independent in situ $K_{\mathrm{v}}$ values calculated from high frequency pressure data changes within a thick, homogenous and laterally extensive clayey-silt deposit. This provides confidence for contaminant transport experiments that 10 require several pore volumes of influent flow at steady state conditions, but would otherwise require implausibly lengthy testing periods without accelerated flow rates.

Further studies are in progress in the CP to measure both $K_{\mathrm{v}}$ and $K_{\mathrm{h}}$ to assess the anisotropy of core samples, to quantify the effect of deionized water and varying influent chemistry on $K_{\mathrm{v}}$, and to consider the significance of transient fluid pres15 sure and changes in stress regimes during accelerated fluid flow in these porous media. Additional instrumentation to monitor changes in moisture content and fluid pressure/suction within the core is required to examine the effects of desaturation on strata integrity and hydraulic behaviour.

Acknowledgements. Funding from the Australian Research Council and National Water Commission, through the National Centre for Groundwater Research and Training Program 1B is gratefully acknowledged. The contributions of N. Baker and A. Ainsworth of Broadbent and Sons, Hudersfield UK, are acknowledged and J. McCartney for helpful discussion on the theory of fluid flow during centrifuge testing. We appreciated research support at the Breeza farm provided by M. McLeod and S. Goodworth of the NSW Department of Primary Industries. Clayeyand G. Regmi. Experimental testing was assisted at UNSW by A. Hartland, B. Bambrook, M. Aitkins, P. King, S. May and T. Meyers.

\section{HESSD}

$11,3155-3212,2014$

\section{Vertical hydraulic conductivity of a clayey-silt aquitard \\ W. A. Timms et al.}

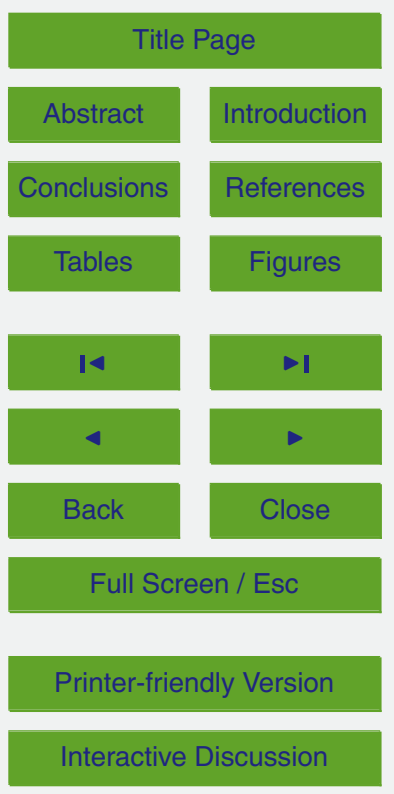




\section{References}

Acworth, R. I.: Investigation of dryland salinity using the electrical image method, Aust. J. Soil Res., 37, 623-636, 1999.

Acworth, R. I. and Timms, W.: Evidence for connected water processes through smectitedominated clays at Breeza, New South Wales, Aust. J. Earth Sci., 56, 71-86, 2009.

Ahn, H. S. and Young Jo, H. Y.: Influence of exchangeable cations on hydraulic conductivity of compacted bentonite, Appl. Clay Sci., 44, 144-150, 2009.

Arulanandan, K., Thompson, P. Y., Kutter, B. L., Meegoda, N. J., Muraleetharan, K. K., and Yogachandran, C.: Centrifuge modeling of transport processes for pollutants in soils,

10 J. Geotech. Eng.-ASCE, 114, 185-205, 1988.

API: Recommended Practices for Core Analysis, Recommended Practice 40, 2nd Edn, American Petroleum Institute Publishing Services, Washington, DC, 1998.

APLNG: Groundwater Assessment, Australia Pacific LNG Upstream Project Phase 1, QLNG01-15-TR-1801, Australia Pacific LNG, Milton, Queensland, Australia, 266 pp., 2013.

15 AS: Methods of Testing Soil for Engineering Purposes, Standard methods 1289 2.1.1; 5.1.1; 5.3.2 and 6.7.3, Australian Standards, Sydney, 1991.

AS: Sampling and Preparation of Soils - Undisturbed Samples - Standard Method 1289 1.3.1. Australian Standards, Sydney, 1999.

ASTM: Standard Test Method for Determining Unsaturated and Saturated Hydraulic Conductivity in Porous Media by Steady State Centrifugation, D 6527-08, American Society for Testing and Materials International, West Conshohocken, PA, United States, 2008.

ASTM: Standard Test Method for Measurement of Hydraulic Conductivity of Unsaturated Soils, D 7664-10, American Society for Testing and Materials International, West Conshohocken, PA, United States, 2010.
Badenhop, A. M. and Timms, W. A.: Long-Term Salinity Changes in an Inland Aquifer, NSW, Australia, in: Proceedings of the 34th Hydrology \& Water Resources Symposium, Engineers Australia, Sydney, NSW, 43-51, 19-22 November 2012.

Bambrook, B.: Aquitards and Groundwater Sustainability - Comparison of Geotechnical Centrifuge Tests and Computer Models, Unpublished Honours thesis, School of Civil and Environmental Engineering, University of New South Wales, 2011.
HESSD

$11,3155-3212,2014$

Vertical hydraulic conductivity of a clayey-silt aquitard

W. A. Timms et al.

Title Page

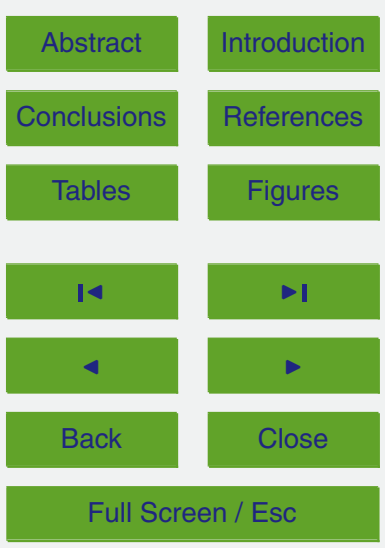

Printer-friendly Version

Interactive Discussion 
Barnett, B., Townley, L. R., Post, V., Evans, R. E., Hunt, R. J., Peeters, L., Richardson, S., Werner, A. D., Knapton, A., and Boronkay, A.: Australian Groundwater Modelling Guidelines, published by the National Water Commission, Australia, 2012.

Boldt-Leppin, B. E. J. and Hendry, J. M.: Application of harmonic analysis of water levels to determine vertical hydraulic conductivities in clay-rich aquitards, Ground Water, 41, 514522, 2003.

Bouzalakos, S., Timms, W., Rahman, P., McGeeney, D., and Whelan, M.: Geotechnical centrifuge permeater for characterizing the hydraulic integrity of partially saturated confining strata for CSG operations, in: Reliable Mine Water Technology, Vol. I, Proceedings of the International Mine Water Congress, Colorado School of Mines, 5-9 August 2013, edited by: Brown, A., Figueroa, L., and Wolkersdorfer, Ch., Publication Printers, Denver, Colorado, USA, 1193-1198, 2013.

Broadbent: Operating Manual for Modular Geotechnical Centrifuge with GT2/0.65 Permeameter and GT6/0.75 Beam Environments, Broadbent and Sons Ltd., Huddersfield, UK, 2011.

15 Cherry, J. A., Parker, B. L., Bradbury, K. R., Eaton, T. T., Gotkowitz, M. G., Hart, D. J., and Borchardt, M. A.: Role of Aquitards in the Protection of Aquifers from Contamination: a "State of the Science" Report, AWWA Research Foundation, Denver, CO, United States, 2004.

Conca, J. L. and Wright, J.: The UFA method for rapid, direct measurements of unsaturated transport properties in soil, sediment and rock, Aust. J. Soil Res., 36, 1-25, 1998.

20 Farley, C.: Aquitards and Groundwater Sustainability: Three-Dimensional Mapping of Aquitard Architecture, Unpublished Honours thesis, School of Civil and Environmental Engineering, University of New South Wales, 2011.

Garnier, J., Gaudin, C., Springman, S. M., Culligan, P. J., Goodings, D., Konig, D., Kutter, B., Phillips, R., Randolph, M. F., and Thorel, L.: Catalogue of scaling laws and similitude questions in geotechnical centrifuge modelling, International Journal of Physical Modelling in Geotechnics, 3, 1-23, 2007.

Geofabrics: bidim ${ }^{\circledR}$ Technical Data Sheet - Nonwoven Polyester Geotextile, M018 02 09, Geofabrics Australasia Pty Ltd, Melbourne, Australia, 2009.

Gerber, R. E. and Howard, K.: Recharge through a regional till aquitard: three-dimensional flow model water balance approach, Ground Water, 38, 410-422, 2000.

Grisak, G. E. and Cherry, J. A.: Hydrologic characteristics and response of fractured till and clay confining a shallow aquifer, Can. Geotech. J., 12, 23-43, 1975.

Head, K. H.: Manual of Soil Laboratory Testing, Pentech Press, London, 1988.
HESSD

11, 3155-3212, 2014

Vertical hydraulic conductivity of a

clayey-silt aquitard

W. A. Timms et al.

Title Page

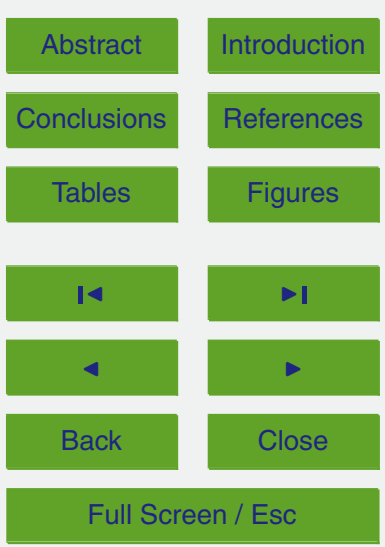

Printer-friendly Version

Interactive Discussion 
Jiang, Z., Mariethoz, G., Taulis, M., and Cox, M.: Determination of vertical hydraulic conductivity of aquitards in a multilayered leaky system using water-level signals in adjacent aquifers, J. Hydrol., 500, 170-182, 2013.

Josh, M., Esteban, L., Delle Piane, C., Sarout, J., Dewhurst, D. N., and Clenell, M. B.: 5 Laboratory characterisation of shale properties, J. Petrol. Sci. Eng., 88, 107-124, doi:10.1016/j.petrol.2012.01.023, 2012.

Jougnot, D., Revil, A., Lu, N., and Wayllace, A.: Transport properties of the CallovoOxfodrian clay rock under partially saturated conditions, Water Resour. Res., 46, W08514, doi:10.1029/2009WR008552, 2010.

10 Kelly, B. F. J., Timms, W. A., Andersen, S. M., Ludowici, K., Blakers, R., Badenhop, A., McCallum, A. M., Rau, G. C., and Acworth, R. I.: Aquifer heterogeneity and response time: the challenge for groundwater management, Crop Pasture Sci., 64, 11411154,doi:10.1071/CP13084, 2013.

Loke, M. H.: Rapid 2-D and 3-D Resistivity and IP Inversion Using the Least Squares Method - RES2DINV Ver 3.4 Manual, available at: www.geoelectrical.com (last access: 18 January 2014), 2001.

McCartney, J. S.: Determination of the Hydraulic Characteristics of Unsaturated Soils Using a Centrifuge Permeameter, Ph.D. thesis, The University of Texas at Austin, Faculty of the Graduate School, 2007.

20 McCartney, J. S. and Zornberg, J. G.: Centrifuge permeameter for unsaturated soils II: measurement of the hydraulic characteristics of an unsaturated clay, J. Geotech. Geoenviron., 136, 1064-1076, 2010.

McNeilage, C.: Upper Namoi Groundwater Flow Model, NSW Department of Natural Resources, New South Wales, Parramatta, 2006.

Nakajima, H. and Stadler, A. T.: Centrifuge modeling of one-step outflow tests for unsaturated parameter estimations, Hydrol. Earth Syst. Sci., 10, 715-729, doi:10.5194/hess-10715-2006, 2006.

Neuman, S. P. and Witherspoon, P. A.: Theory of flow in aquicludes adjacent to slightly leaky aquifers, Water Resour. Res., 4, 103-112, 1968.

30 Neuman, S. P. and Witherspoon, P. A.: Field determination of the hydraulic properties of leaky multiple aquifer systems, Water Resour. Res., 8, 1284-1298, 1972.

Neuzil, C. E.: Groundwater flow in low permeability environments, Water Resour. Res., 22, 1163-1195, 1986.
HESSD

$11,3155-3212,2014$

Vertical hydraulic conductivity of a clayey-silt aquitard

W. A. Timms et al.

Title Page

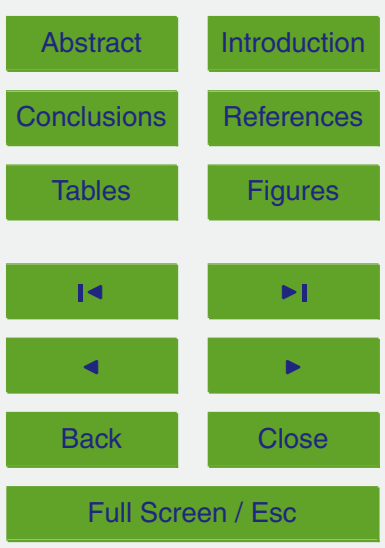

Printer-friendly Version

Interactive Discussion 
Neuzil, C. E.: How permeable are clays and shales?, Water Resour. Res., 30, 145-150, 1994.

Nimmo, J. R. and Mello, K. A.: Centrifugal techniques for measuring saturated hydraulic conductivity, Water Resour. Res., 27, 1263-1269, 1991.

Nimmo, J. R., Rubin, J., and Hammermeister, D. P.: Unsaturated flow in a centrifugal field: 5 measurement of hydraulic conductivity and testing of Darcy's Law, Water Resour. Res., 23, 124-134, 1987.

Parks, J., Stewart, M., and McCartney, J. S.: Validation of a centrifuge permeameter for investigation of transient infiltration and drainage flow processes in unsaturated soils, Geotech. Test. J., 35, Paper ID: GTJ103625, doi:10.1520/GTJ103625, 2012.

10 Potter, P. E., Maynard, J. B., and Pryor, W. A.: Sedimentology of Shale - Study Guide and Reference Source, Springer-Verlag, New York, 1980.

Rowe, R. K., Quigley, R. M., and Booker, J. R.: Clayey Barrier Systems for Waste Disposal Facilities, E\& FN Spon, London, 1995.

Schulze-Makuch, D., Carlson, D. A., Cherkauer, D. S., and Malik, P.: Scale Dependency of 15 hydraulic conductivity in heterogeneous media, Ground Water, 37, 904-919, 1999.

Shackelford, C. D., Sevick, G. W., and Eykholt, G. R.: Hydraulic conductivity of geosynthetic clay liners to tailings impoundment solutions, Geotext. Geomembranes, 28, 149-162, 2010.

Šimůnek, J. and Nimmo, J.: Estimating soil hydraulic parameters from transient flow experiments in a centrifuge using parameter optimization technique, Water Resour. Res., 41, 1-9, 202005.

Singh, D. N. and Gupta, A. K.: Modelling hydraulic conductivity in a small centrifuge, Can. Geotech. J. 37, 1150-1155, 2000.

Smith, L. A., van der Kamp, G., and Hendry, M. J.: A new technique for obtaining high-resolution pore pressure records in thick claystone aquitards and its use to determine in situ compressibility, Water Resour. Res., 9, 732-743, 2013.

Sundaram, B., Feitz, A., de Caritat, P., Plazinska, A., Brodie, R., Coram, J., and Ransley, T.: Groundwater Sampling and Analysis - a Field Guide, Geoscience Australia, Record 2009/27, 95 pp., 2009.

Tan, T. S. and Scott, R. F.: Centrifuge scaling considerations for fluid-particle systems: discussion by R. N. Taylor and response, Geotechnique, 37, 131-133, 1987.

Timms, W. and Acworth, R. I.: Propagation of porewater pressure change through thick clay sequences: an example from the Yarramanbah site, Liverpool Plains, New South Wales, Hydrogeol. J., 13, 858-870, doi:10.1007/s10040-005-0436-7, 2005.

Vertical hydraulic conductivity of a clayey-silt aquitard

W. A. Timms et al.

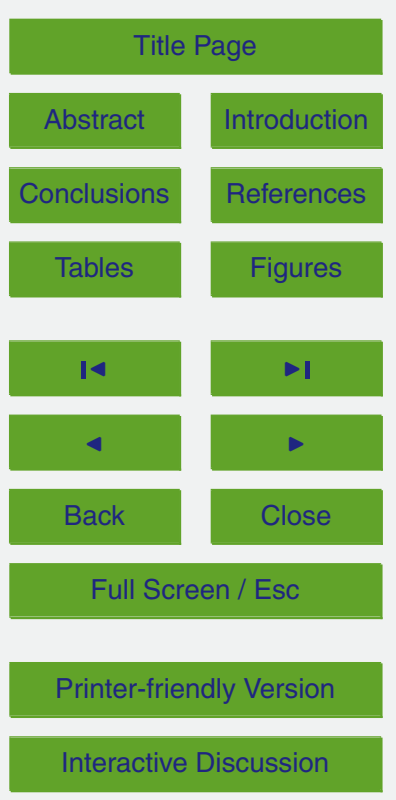


Timms, W. and Acworth, R. I.: Rethinking a Conceptual Model: Advective vs. Diffusive Chloride Flux in a Low Permeability Clay Sequence, International Association of Hydrogeologists Congress on Aquifer Systems Management, Dijon, France, 30 May-1 June, 2006.

Timms, W. A. and Hendry, M. J.: Long term reactive solute transport in an aquitard using a centrifuge model, Ground Water, 46, 616-628, doi:10.1111/j.1745-6584.2008.00441.x, 2008.

Timms, W. A., Hendry, M. J., Sharma, J., and Cooper, C: Application of centrifuge modelling to assess long-term brine migration in thick clay tills, Saskatchewan, Canada, in: Proceedings of Water in Mining, Australian Institute of Mining and Metallurgy (AusIMM), Brisbane, 1315 October 2003, 2003.

10 Timms, W., Hendry, J., Muise, J., and Kerrich, R.: Coupling centrifuge modeling and laser ablation ICP-MS to determine contaminant retardation in clays, Environ. Sci. Technol., 43, 11531159, 2009.

Timms, W., Acworth, I., Hartland, A., and Laurence, D.: Leading practices for assessing the integrity of confining strata: application to mining and coal seam gas extraction, in: International Water and Mining Association Symposium Proceedings, Bunbury, Western Australia, 29 September to 4 October 2012, edited by: Clint, D., McCullough, C. D., Lund, M. A., and Wyse, L., 139-148, 2008.

Timms, W., Whelan, M., Acworth, I., McGeeney, D., Bouzalakos, S., Crane, R., McCartney, J., and Hartland, A.: A novel centrifuge permeameter to characterize flow through low permeability strata, in: Proceedings of International Congress on Physical Modelling in Geotechnics (ICPMG), Perth, Balkema, 14-17 January, 2014.

US EPA: Requirement for Hazardous Waste Landfill Design, Construction and Closure, EPA/625/4-89/022, US Environmental Protection Agency, Cincinnati, OH, United Sates, 1989.

Van der Kamp, G.: Methods for determining the in situ hydraulic conductivity of shallow aquitards - an overview, J. Hydrol., 9, 5-6, 2001.

Van der Kamp, G.: Determining the hydraulic properties of aquitards, in: 2nd Canadian Symposium on Aquitard Hydrogeology, University of Ottawa, Canada, 21-23 June, 2011.

Wiesner, T. and Acworth, R. I.: Groundwater Contamination Investigation Using CCPTs, Water 99 Joint Congress, Brisbane, Australia, 6-8 July, 1999.

Wright, M., Dillon, P., Pavelic, P., Peter, P., and Nefiodovas, A.: Measurement of 3-D hydraulic conductivity in aquifer cores at in situ effective stress, Ground Water, 40, 509-517, 2002.

\section{HESSD}

11, 3155-3212, 2014

Vertical hydraulic conductivity of a clayey-silt aquitard

W. A. Timms et al.

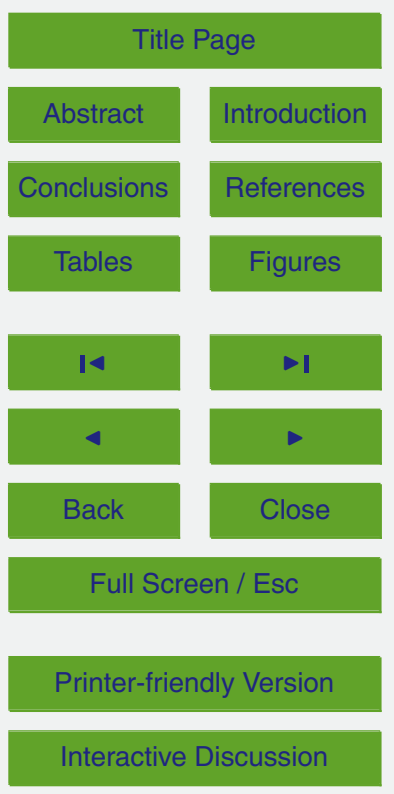


Zornberg, J. G. and McCartney, J. S.: Centrifuge permeameter for unsaturated soils. I: Theoretical basis and experimental developments, J. Geotech. Geoenviron., 136, 1051-1063, 2010.

Znidarčić, D., Miller, R., van Zyl, D., Fredlund, M., and Wells, S.: Consolidation testing of oil sand 5 fine tailings, in: Proceedings Tailings and Mine Waste 2011, Vancouver, BC, 6-9 November, 2011.

\section{HESSD}

$11,3155-3212,2014$

Vertical hydraulic conductivity of a clayey-silt aquitard

W. A. Timms et al.

Title Page

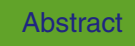

Conclusions

Tables

14

4

Back
Introduction

References

Figures

1

$>$

Close

Full Screen / Esc

Printer-friendly Version

Interactive Discussion 


\section{HESSD}

11, 3155-3212, 2014

Vertical hydraulic conductivity of a

Table 1. Fluid flow setups and types of tests for centrifuge permeameters.

\begin{tabular}{lll}
\hline Flow setup & Test types & Selected examples \\
\hline No inflow & $\begin{array}{l}\text { Compressibility and set- } \\
\text { tlement, specific storage, } \\
\text { pore water extraction }\end{array}$ & $\begin{array}{l}\text { Lee and Fox (2006); Sacchi et al. (2001); Ed- } \\
\text { munds and Bath (1976). }\end{array}$ \\
\hline Steady flow & $\begin{array}{l}\text { Permeability, advective } \\
\text { solute transport (reactive } \\
\text { or conservative), effec- } \\
\text { tive porosity, swelling of } \\
\text { expansive clay }\end{array}$ & $\begin{array}{l}\text { Plaisted al. (2009); Timms et al. (2003); Arandulan } \\
\text { et al. (1998). }\end{array}$ \\
& $\begin{array}{ll}\text { Permeability, water reten- } \\
\text { tion curve }\end{array}$ & $\begin{array}{l}\text { Parks et al. (2012); Zornberg and McCart- } \\
\text { ney (2010); McCartney (2007); Nakajima and } \\
\text { Transient flow }\end{array}$ \\
& & Stadler (2006); Simunek and Nimmo (2005); \\
& Conca and Wright (1998). \\
\hline
\end{tabular}

clayey-silt aquitard

W. A. Timms et al.

Title Page

Abstract

Introduction

Conclusions

References

Tables

Figures

14

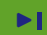

4

Back

Full Screen / Esc

Printer-friendly Version

Interactive Discussion 
Table 2. Specifications and performance details of the Broadbent GT-18 centrifuge permeameter (CP) system as constructed by Broadbent (2011).

\begin{tabular}{ll}
\hline Dimensions/mass & \\
\hline Diameter (lower rotary stack) & $200.0 \mathrm{~cm}$ \\
Radius to top sample chamber & $45.0 \mathrm{~cm}^{\mathrm{a}}$ \\
Radius to base sample chamber & $65.0 \mathrm{~cm}^{\mathrm{b}}$ \\
Total mass & $4800 \mathrm{~kg}$ \\
\hline Performance & \\
\hline Rotational speed & $10-875 \mathrm{RPM}$ \\
Maximum sample length & $20.0 \mathrm{~cm}$ \\
Maximum sample diameter & $10.0 \mathrm{~cm}$ \\
Maximum sample mass & $4.7 \mathrm{~kg}$ \\
Maximum sample density & $S G 3.0$ \\
Maximum effluent reservoir capacity & $1000 \mathrm{~mL}$ \\
Maximum payload & $18.11 \mathrm{~kg}$ \\
\hline
\end{tabular}

a $385 \mathrm{G}$ at 875 RPM.

${ }^{\mathrm{b}} 556 \mathrm{G}$ at $875 \mathrm{RPM}$.
Vertical hydraulic conductivity of a clayey-silt aquitard

W. A. Timms et al.

Title Page

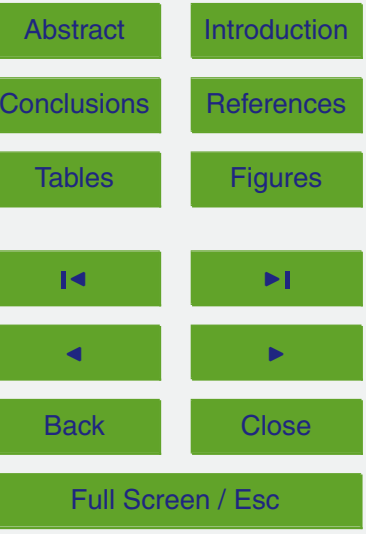

Printer-friendly Version

Interactive Discussion 
Table 3. Core descriptions and index properties.

\begin{tabular}{|c|c|c|c|c|c|}
\hline Core ID & $\begin{array}{l}\mathrm{BF} \\
\mathrm{C} 2.8\end{array}$ & $\begin{array}{l}\mathrm{BF} \\
\mathrm{C} 2.16 \& \mathrm{C} 2.15\end{array}$ & $\begin{array}{l}\mathrm{CL} \\
\mathrm{C} 4.8 \mathrm{a}\end{array}$ & $\begin{array}{l}\mathrm{CL} \\
\mathrm{C} 4.20 \mathrm{a}\end{array}$ & $\begin{array}{l}\mathrm{NR} \\
\mathrm{C} 3.23\end{array}$ \\
\hline Depth (mb.g.I.) & $\begin{array}{l}11.00-11.35 / \\
11.35-11.68\end{array}$ & $\begin{array}{l}22.50-22.90 / \\
21.93-22.18\end{array}$ & $11.27-11.47$ & $28.50-28.70$ & $\begin{array}{l}33.00-33.35 / \\
33.35-33.68\end{array}$ \\
\hline Description & Sandy clay - brown & Clayey silt - brown & Silty clay - brown & $\begin{array}{l}\text { Silty clay - pale } \\
\text { brown }\end{array}$ & Clayey silt - brown \\
\hline $\begin{array}{l}\text { Field moisture } \\
\text { content }(\%)\end{array}$ & 24.7 & 28.2 & 45.7 & 36.4 & - \\
\hline $\mathrm{D}_{50}(\mathrm{~mm})$ & 0.025 & 0.0068 & - & - & $<0.0013$ \\
\hline $\begin{array}{l}\text { Bulk density } \\
\left(\mathrm{g} \mathrm{cm}^{-3}\right)\end{array}$ & 1.88 & 1.81 & 1.71 & 1.77 & 1.72 \\
\hline $\begin{array}{l}\text { Particle density } \\
\left(\mathrm{g} \mathrm{cm}^{-3}\right)\end{array}$ & 2.52 & 2.47 & 2.58 & 2.50 & 2.58 \\
\hline Initial void ratio & 0.72 & 0.82 & 1.31 & 1.01 & 0.847 \\
\hline $\begin{array}{l}\text { Initial degree of } \\
\text { saturation (\%) }\end{array}$ & 90 & 87 & 99.9 & 100 & 76.5 \\
\hline
\end{tabular}

\section{HESSD}

11, 3155-3212, 2014

Vertical hydraulic conductivity of a clayey-silt aquitard

W. A. Timms et al.

\section{Title Page}

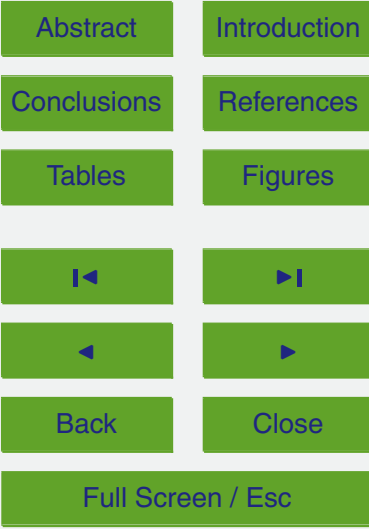

Printer-friendly Version

Interactive Discussion 
Table 4. $K_{\mathrm{v}}$ results from CP tests indicating $g$-level maximum and testing time. The influent source column identifies the site (NR, CL, BF) and depth (P20 is piezometer screen at $20 \mathrm{~m}$ depth) of groundwater sampling. Calculations were based on Eq. (9) for $K_{\mathrm{v}}$ and Eq. (11) for in situ stress.

\begin{tabular}{llllllll}
\hline Site & $\begin{array}{l}\text { Test } \\
\text { ID }\end{array}$ & $\begin{array}{l}\text { Depth } \\
(\mathrm{mb.g.I.})\end{array}$ & $K_{\mathrm{v}}\left(\mathrm{m} \mathrm{s}^{-1}\right)$ & $\begin{array}{l}g \text {-level } \\
\text { maximum }\end{array}$ & $\begin{array}{l}\text { Estimated in situ } \\
\text { stress }(\mathrm{kPa})\end{array}$ & $\begin{array}{l}\text { Testing } \\
\text { time }(\mathrm{h})\end{array}$ & $\begin{array}{l}\text { Influent } \\
\text { source }\end{array}$ \\
\hline $\mathrm{NR}$ & $5-1$ & 33.8 & $4 \times 10^{-9}$ & 10 & 615 & $\sim 144$ & NR P30 \\
NR & $5-2$ & 33.9 & $2 \times 10^{-9}$ & 10 & 615 & $\sim 144$ & NR P30 \\
NR & $37-1$ & 34.68 & $2.4 \times 10^{-7}$ & 10 & 646 & 2.6 & NR P30 \\
\hline CL & $36-1$ & 11.75 & $3.5 \times 10^{-9}$ & 80 & 219 & 24 & CL P15 \\
CL & $36-2$ & 19.25 & $2.0 \times 10^{-9}$ & 80 & 359 & 24 & CL P20 \\
CL & $39-1$ & 26.01 & $2.4 \times 10^{-9}$ & 80 & 485 & 21 & CL P40 \\
CL & $39-2$ & 26.10 & $1.1 \times 10^{-10}$ & 80 & 486 & 21 & CL P40 \\
CL & $53-1$ & 28.33 & $2.0 \times 10^{-9}$ & 10 & 526 & 24 & CL P40 \\
\hline BF & $34-1$ & 24.07 & $5.9 \times 10^{-9}$ & 40 & 449 & 3 & BF CP25 \\
BF & $34-2$ & 24.14 & $3.4 \times 10^{-8}$ & 40 & 450 & 3 & BF CP25 \\
BF & $53-2$ & 31.4 & $1.3 \times 10^{-9}$ & 30 & 567 & 11.1 & BF CP40 \\
BF & $37-2$ & 36.46 & $3.5 \times 10^{-7}$ & 10 & 680 & 2.5 & BF CP40 \\
BF & $35-1$ & 40 & $1.5 \times 10^{-9}$ & 30 & 746 & 23 & BF CP40 \\
BF & $35-2$ & 40 & $4.3 \times 10^{-8}$ & 30 & 746 & 23 & BF CP40 \\
\hline
\end{tabular}

Vertical hydraulic conductivity of a clayey-silt aquitard

W. A. Timms et al.

Title Page

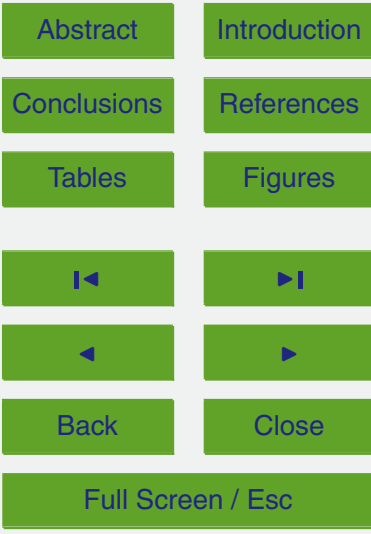

Printer-friendly Version

Interactive Discussion 
Vertical hydraulic conductivity of a clayey-silt aquitard

W. A. Timms et al.

Table 5. Independent $1 \mathrm{~g}$ column permeameter results (vertical uniaxial stress $100 \mathrm{kPa}$, influent was water that was deionized by distillation).

\begin{tabular}{llll}
\hline $\begin{array}{l}\text { Core } \\
\text { Site }\end{array}$ & $\begin{array}{l}\text { Depth } \\
(\mathrm{mb} \text { b.l. })\end{array}$ & $\begin{array}{l}\text { Apparent } K_{\mathrm{v}} \\
\left(\mathrm{ms}^{-1}\right)\end{array}$ & $\begin{array}{l}\text { Testing time } \\
(\mathrm{h})\end{array}$ \\
\hline $\mathrm{CL}$ & $11.27-11.47$ & $1.4 \times 10^{-9}$ & 96 \\
$\mathrm{CL}$ & $11.27-11.47$ & $1.1 \times 10^{-10}$ & 73 \\
$\mathrm{CL}$ & $28.24-28.33$ & $1.5 \times 10^{-10}$ & 100 \\
\hline
\end{tabular}

Title Page

Abstract Introduction

Conclusions References

Tables Figures

14

4

Back

Full Screen / Esc

Printer-friendly Version

Interactive Discussion 
Table 6. Linear flow velocity at natural gradient, unit gradient and for various centrifuge permeameter setups.

\begin{tabular}{|c|c|c|c|c|c|}
\hline & $\begin{array}{l}\text { Natural } \\
\text { gradient }\end{array}$ & $\begin{array}{l}\text { Unit } \\
\text { gradient }\end{array}$ & $\begin{array}{l}\text { Centrifuge } \\
\text { permeameter }\end{array}$ & & \\
\hline $\begin{array}{l}\text { Vertical hydraulic } \\
\text { conductivity }\left(\mathrm{ms}^{-1}\right)\end{array}$ & & & $1.0 \times 10^{-8}$ & & \\
\hline Core type & \multicolumn{3}{|c|}{ C core - long } & C core - short & $\begin{array}{l}\mathrm{HQ} \text { core } \\
- \\
\text { short }\end{array}$ \\
\hline $\begin{array}{l}\text { Core length } \times \\
\text { diameter }(\mathrm{mm})\end{array}$ & \multicolumn{3}{|c|}{$200 \times 100$} & $30 \times 100$ & $30 \times 65$ \\
\hline RPM & $\mathrm{n} / \mathrm{a}$ & $\mathrm{n} / \mathrm{a}$ & 202 & 202 & 310 \\
\hline$g$-level & 1 & 1 & 30 & 30 & 70 \\
\hline $\begin{array}{l}\text { Vertical fluid head } \\
\text { gradient }\left(\mathrm{m} \mathrm{m}^{-1}\right)\end{array}$ & 0.5 & 1 & $\sim 0.2^{*}$ & $\sim 0.5^{*}$ & $\sim 0.5^{*}$ \\
\hline Flow $\left(m L h^{-1}\right)$ & 0.3 & 0.6 & 8.5 & 8.5 & 8.5 \\
\hline $\begin{array}{l}\text { Linear flow } \\
\text { velocity }\left(\mathrm{ms}^{-1}\right)\end{array}$ & $1.7 \times 10^{-8}$ & $3.3 \times 10^{-8}$ & $1.0 \times 10^{-6}$ & $1.0 \times 10^{-6}$ & $\begin{array}{l}2.4 \times \\
10^{-6}\end{array}$ \\
\hline \multirow{2}{*}{$\begin{array}{l}\text { Time for } 1 \text { pore } \\
\text { volume }(h)\end{array}$} & 3333 & 1667 & 55.4 & 8.3 & 3.5 \\
\hline & & & \multicolumn{2}{|l|}{ Normalised } & \\
\hline $\begin{array}{l}\text { Increased linear } \\
\text { flow velocity }\end{array}$ & & & 30 & 30 & 71 \\
\hline $\begin{array}{l}\text { Reduced time for } \\
1 \mathrm{PV}\end{array}$ & & & 30 & 200 & 474 \\
\hline
\end{tabular}

* Fluid head gradient depends on the depth of influent on the core, and the length of the core.

\section{HESSD}

11, 3155-3212, 2014

Vertical hydraulic conductivity of a clayey-silt aquitard

W. A. Timms et al.

Title Page

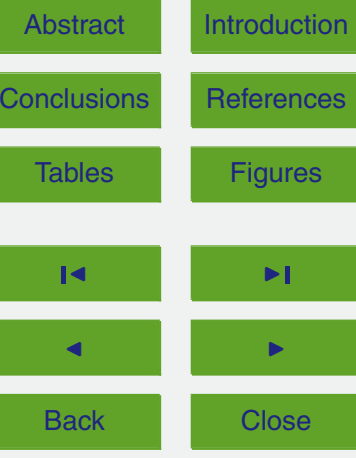

Full Screen / Esc

Printer-friendly Version

Interactive Discussion 


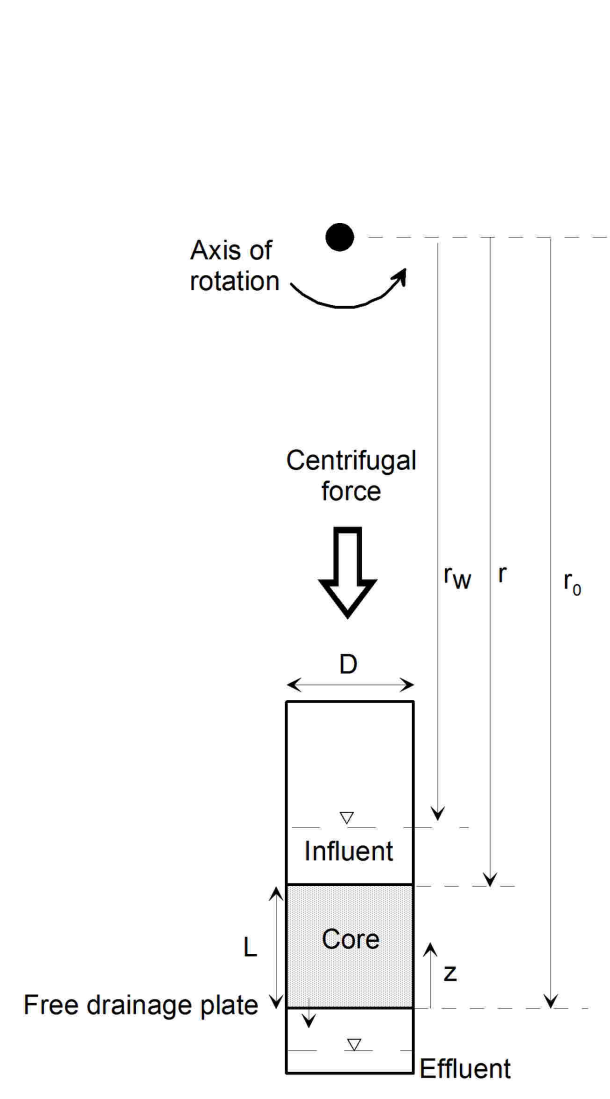

\section{HESSD}

11, 3155-3212, 2014

Vertical hydraulic conductivity of a clayey-silt aquitard

W. A. Timms et al.

Title Page

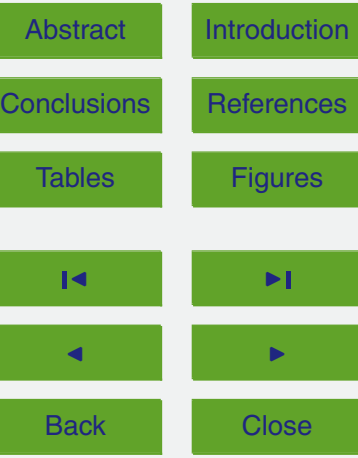

Full Screen / Esc

Fig. 1. Cross-sectional diagram of a core sample subjected to centrifugal force, with a free drainage boundary condition at the base of the core.

Printer-friendly Version

Interactive Discussion 


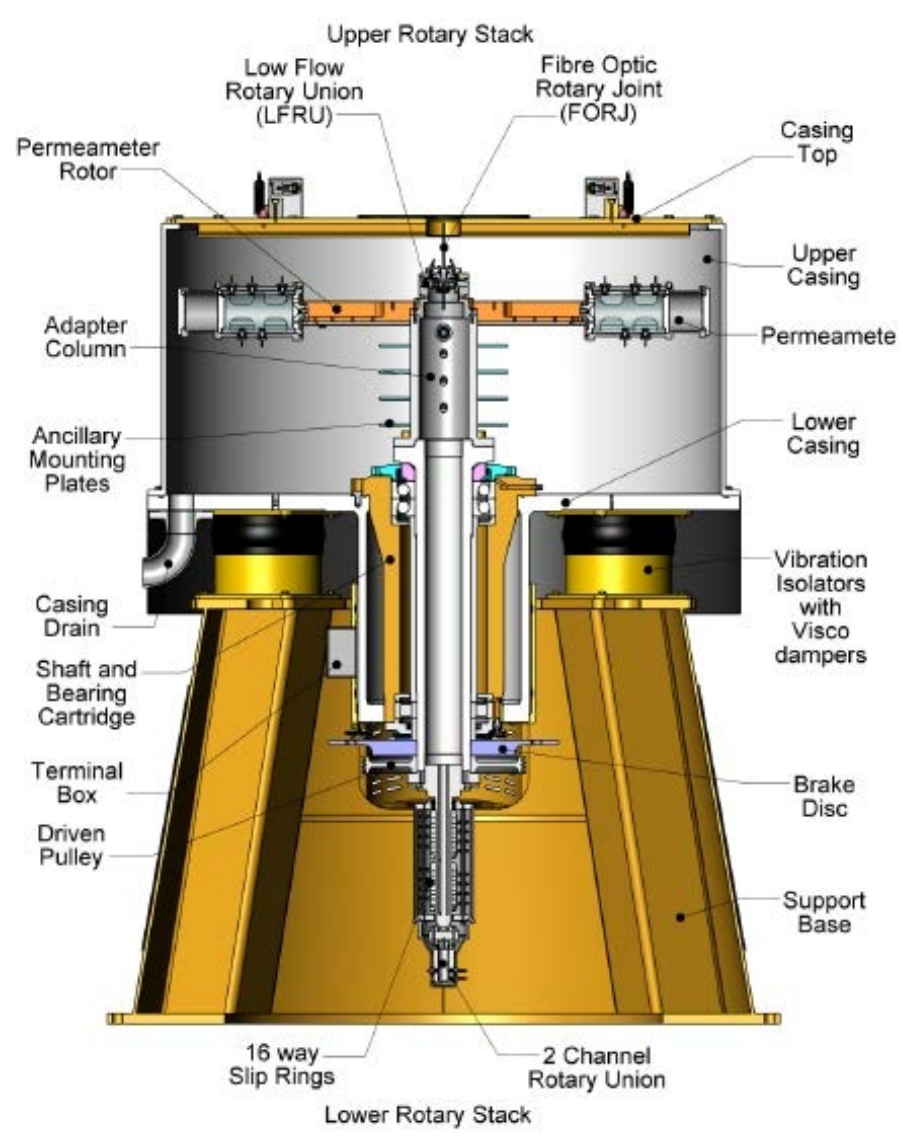

Fig. 2. Schematic diagram of the NCGRT geotechnical centrifuge and permeameter module in cross-section (Broadbent, 2011).

\section{HESSD}

11, 3155-3212, 2014

Vertical hydraulic conductivity of a clayey-silt aquitard

W. A. Timms et al.

\section{Title Page}

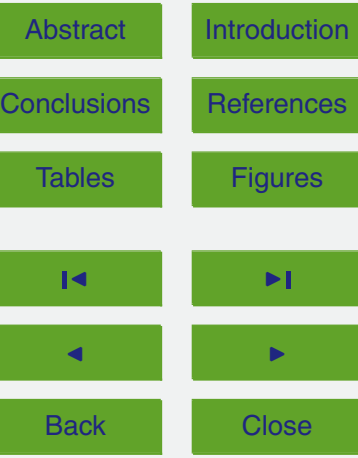

Full Screen / Esc

Printer-friendly Version

Interactive Discussion 

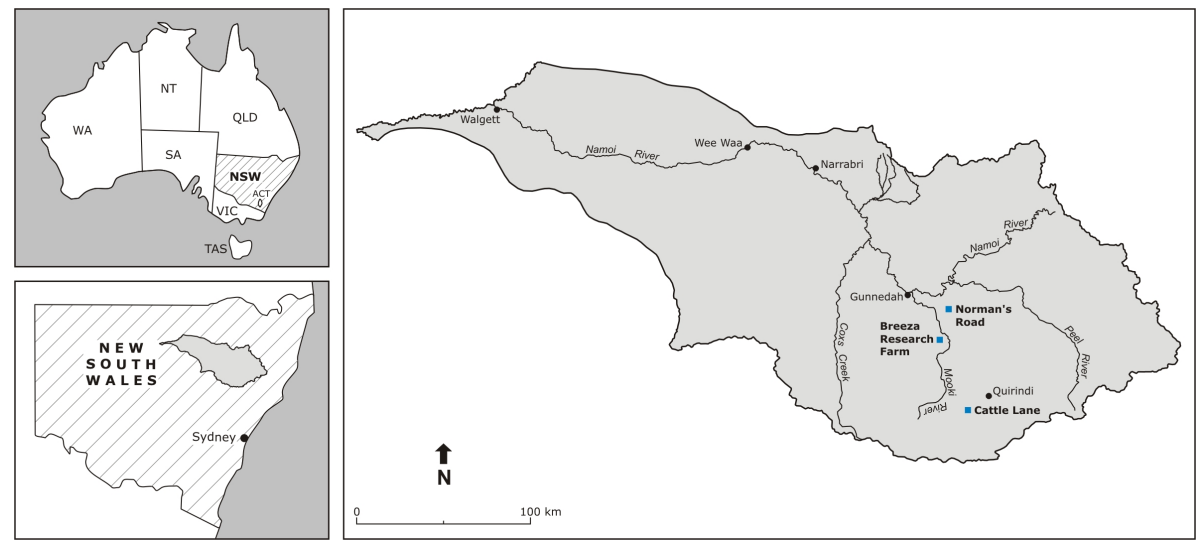

Fig. 3. Location of study sites in Eastern Australia, state of NSW. The Norman's Road, Breeza Farm and Cattle Lane sites are shown within the Namoi catchment.

\section{HESSD}

11, 3155-3212, 2014

Vertical hydraulic conductivity of a clayey-silt aquitard

W. A. Timms et al.

Title Page

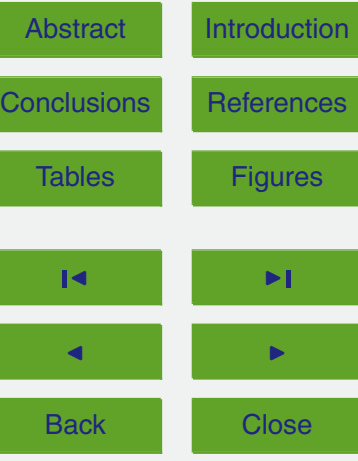

Full Screen / Esc

Printer-friendly Version

Interactive Discussion 


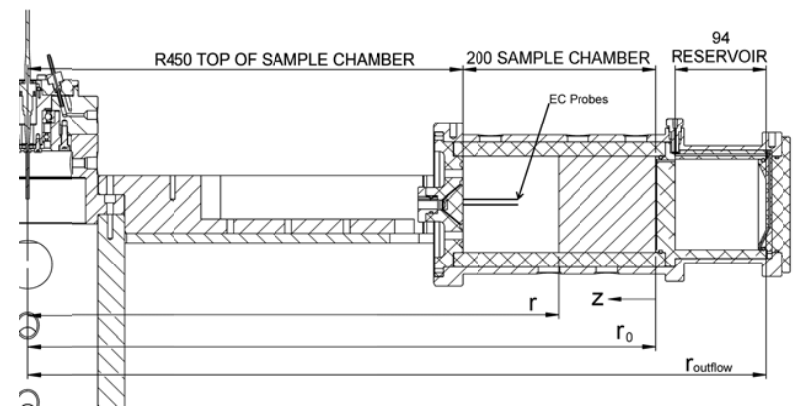

11, 3155-3212, 2014

Vertical hydraulic conductivity of a clayey-silt aquitard

W. A. Timms et al.

(b)

Title Page

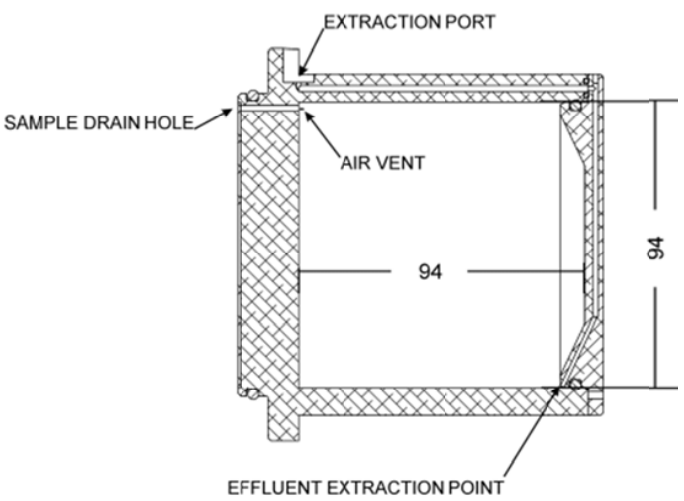

Abstract

Introduction

Conclusions

References

Tables

Figures

14

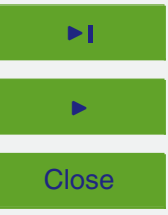

Back

Close

Full Screen / Esc

Printer-friendly Version

Fig. 4. Cross section of the (a) centrifuge permeameter and beam showing new reservoir and reference points and (b) detail of new reservoir liner with suction extraction port. 

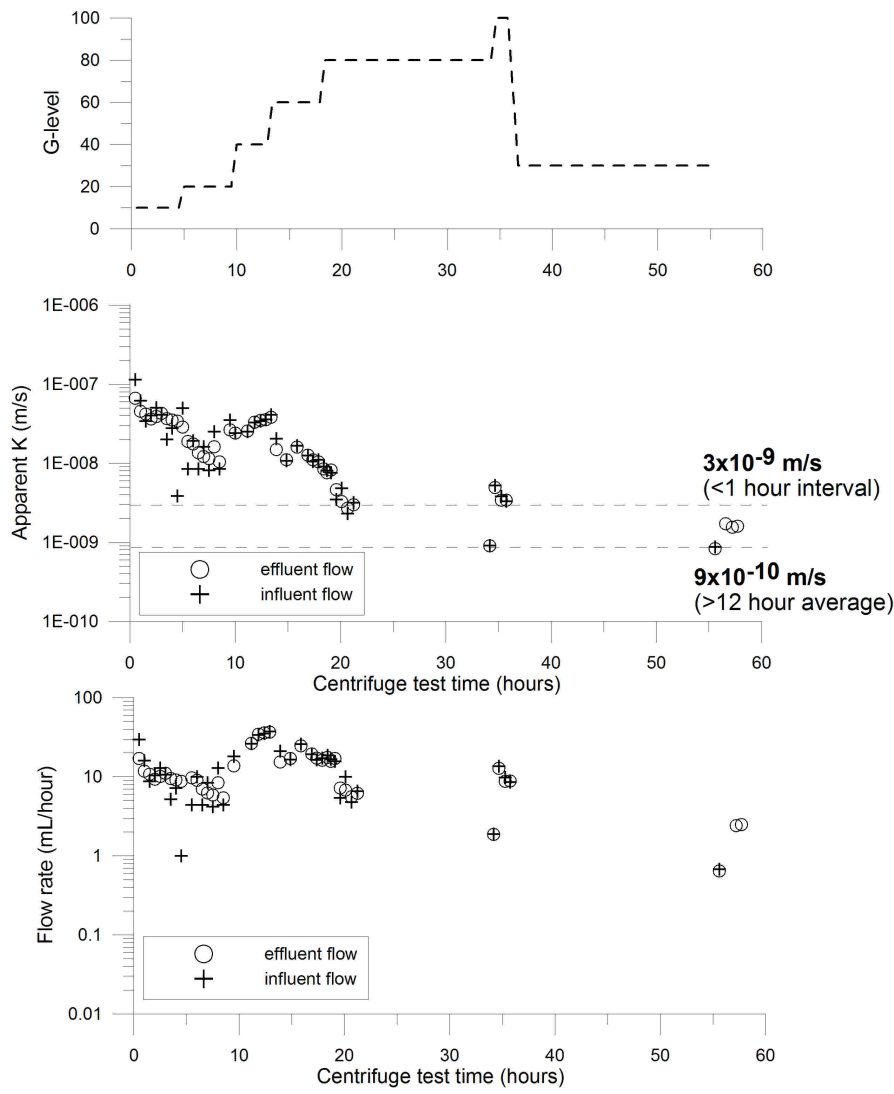

Fig. 5. Centrifuge permeameter testing at low stresses of a semi-consolidated clayey-silt core sample (CL $26.1 \mathrm{~m}$ depth, Test 39-1) showing variation of $g$-level, $K_{\mathrm{v}}$ and influent and effluent flow rate during the test (after Timms et al., 2014).
HESSD

11, 3155-3212, 2014

Vertical hydraulic conductivity of a clayey-silt aquitard

W. A. Timms et al.

Title Page

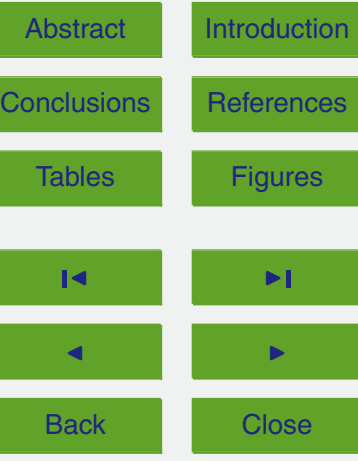

Full Screen / Esc

Printer-friendly Version

Interactive Discussion 


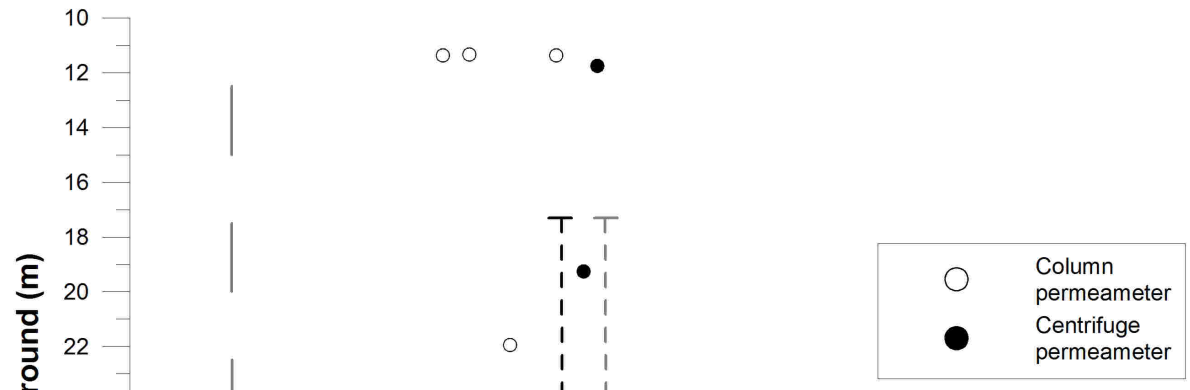

$11,3155-3212,2014$

Vertical hydraulic conductivity of a clayey-silt aquitard

W. A. Timms et al.

\section{Title Page}

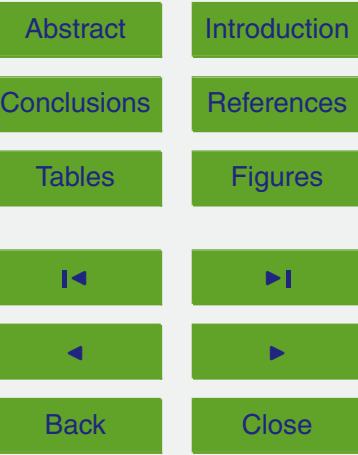

Full Screen / Esc

Fig. 6. Vertical hydraulic conductivity measurements by centrifuge permeameter, column permeameter. These data are compared with in situ pore pressure data at 6 hourly intervals over 5 years interpreted with harmonic analysis (after Timms and Acworth, 2005) for the Cattle Lane site with massive clayey-silt from the surface to $35 \mathrm{~m}$ depth.

Printer-friendly Version

Interactive Discussion 


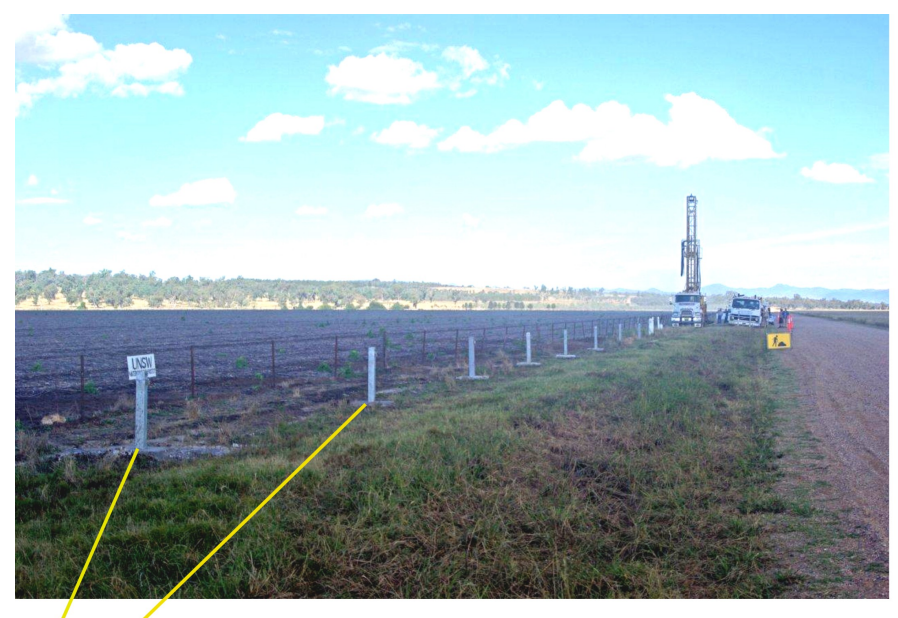

HESSD

11, 3155-3212, 2014

Vertical hydraulic conductivity of a clayey-silt aquitard

W. A. Timms et al.

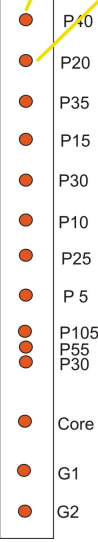

Bulk electrical conductivity image along Cattle Lane, centered on P55

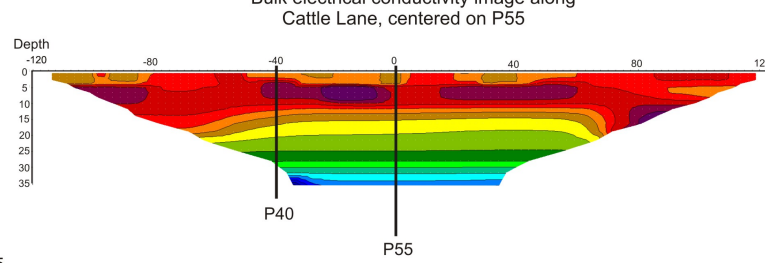

Model of bulk electrical conductivity $(\mathrm{mS} / \mathrm{m})$

$\square_{104.8} \square_{136.2} \square_{177.0} \square_{230.0} \square_{29.0} \square_{389.5} \square_{504.8} \square_{656.0}$

Fig. 7. Electrical resistivity tomography of the Cattle Lane site including a photograph and schematic of the site. Lateral homogeneity of the subsurface alluvium over at least 240 metres is indicated.

Title Page

Abstract Introduction

Conclusions

References

Tables

Figures

14

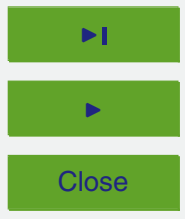

Back

Close

Full Screen / Esc

Printer-friendly Version

Interactive Discussion

(c) (1) 
(a)

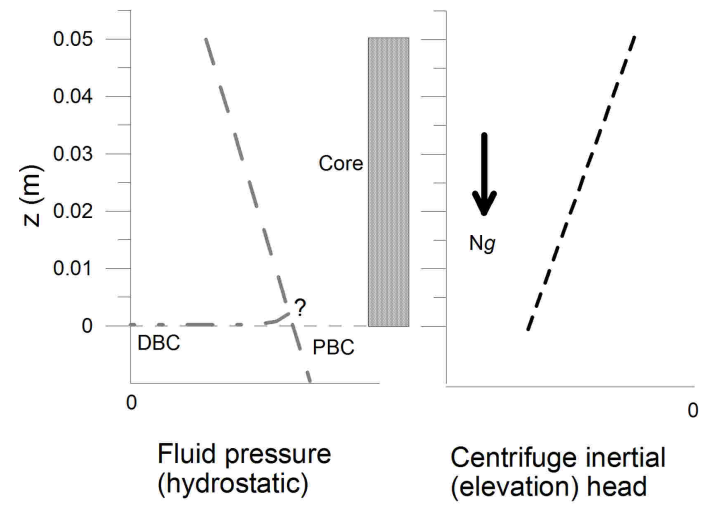

(b)

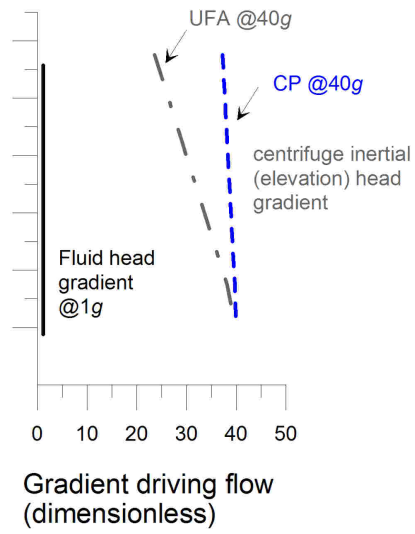

Fig. 8. (a) Conceptual relationship between hydrostatic fluid pressure, centrifuge inertial (elevation) head for a core in a centrifuge permeameter as a function of $z$ (Fig. 1). The direction of centrifugal acceleration and fluid flow is indicated by the arrow $\mathrm{Ng}$. Alternative drainage boundary condition (DBC) and pressure boundary condition (PBC) are indicated at the base of the core sample. (b) Fluid head gradient at $1 g$ and centrifuge inertial head gradients for the UFA and Broadbent (CP module) centrifuges at $40 \mathrm{~g}$.

\section{HESSD}

11, 3155-3212, 2014

\section{Vertical hydraulic conductivity of a clayey-silt aquitard}

W. A. Timms et al.

\section{Title Page}

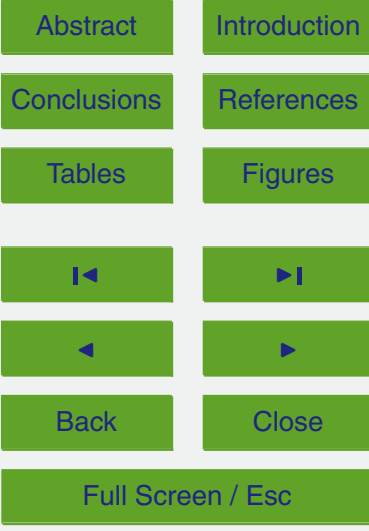

Printer-friendly Version

Interactive Discussion 


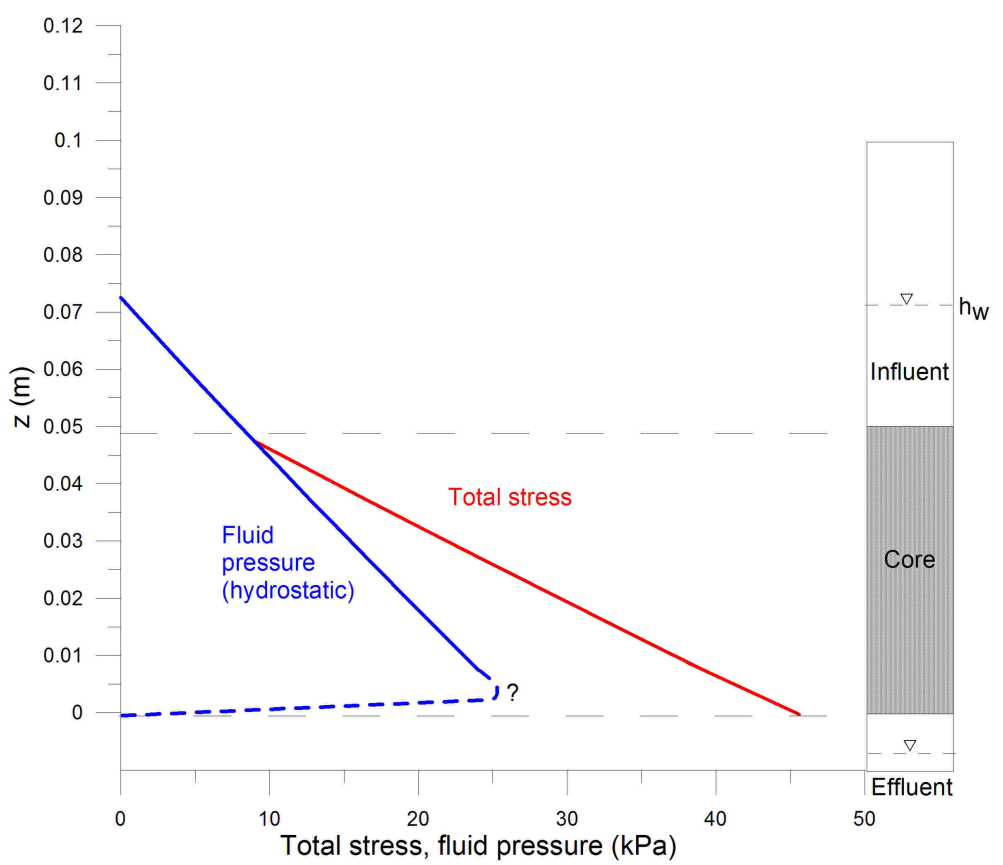

Fig. 9. Fluid head pressure (hydrostatic), total stress and effective stress (difference between total stress and effective stress) at $40 \mathrm{~g}$ in this study.

\section{HESSD}

11, 3155-3212, 2014

Vertical hydraulic conductivity of a clayey-silt aquitard

W. A. Timms et al.

Title Page

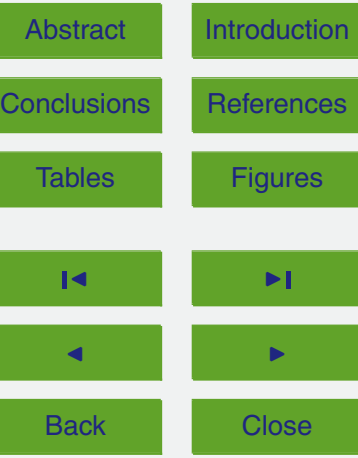

Full Screen / Esc

Printer-friendly Version

Interactive Discussion 